\title{
Correlating microstructure and activity for polysulfide reduction and oxidation at WS2
} electrocatalysts

\author{
Stephens, Ifan E.L.; Ducati, Caterina; Fray, Derek J.
}

Published in:

Journal of The Electrochemical Society

Link to article, DOI:

10.1149/2.027306jes

Publication date:

2013

Document Version

Publisher's PDF, also known as Version of record

Link back to DTU Orbit

Citation (APA):

Stephens, I. E. L., Ducati, C., \& Fray, D. J. (2013). Correlating microstructure and activity for polysulfide reduction and oxidation at WS electrocatalysts. Journal of The Electrochemical Society, 160(6), A757-A768. https://doi.org/10.1149/2.027366jes

\section{General rights}

Copyright and moral rights for the publications made accessible in the public portal are retained by the authors and/or other copyright owners and it is a condition of accessing publications that users recognise and abide by the legal requirements associated with these rights.

- Users may download and print one copy of any publication from the public portal for the purpose of private study or research.

- You may not further distribute the material or use it for any profit-making activity or commercial gain

- You may freely distribute the URL identifying the publication in the public portal 


\title{
Correlating Microstructure and Activity for Polysulfide Reduction and Oxidation at $\mathrm{WS}_{2}$ Electrocatalysts
}

\author{
Ifan E. L. Stephens, ${ }^{*}, \mathrm{a}, \mathrm{z}$ Caterina Ducati, and Derek J. Fray* \\ Department of Materials Science and Metallurgy, University of Cambridge, Pembroke Street, CB2 3QZ Cambridge, \\ United Kingdom
}

\begin{abstract}
The polysulfide reduction and oxidation activity of $\mathrm{WS}_{2}$ electrocatalysts was studied. This was undertaken with a specific view to improve the efficiency of the polysulfide-bromine redox flow battery, for large scale energy storage. Using data from the literature, it is estimated that the catalysts would require exchange current densities of $\sim 0.7$ to $1 \mathrm{~mA} \mathrm{~cm}^{-2}$ true microscopic surface area to enable them to become economically viable. The experiments were performed upon three different forms of $\mathrm{WS}_{2}$ : platelet like particles of the $2 \mathrm{H}$ polytype of $\mathrm{WS}_{2}\left(2 \mathrm{H}-\mathrm{WS}_{2}\right)$, ball milled $\mathrm{WS}_{2}$ and inorganic fullerene-like $\mathrm{WS}_{2}\left(\mathrm{IF}_{-}-\mathrm{WS}_{2}\right)$. The catalysts were characterized ex-situ using X-ray diffraction, scanning electron microscopy, transmission electron microscopy, energy dispersive $\mathrm{X}$-ray analysis and $\mathrm{N}_{2}$ gas adsorption methods. Electrochemical measurements were performed at $35^{\circ} \mathrm{C}$, in aqueous solutions of $1.8 \mathrm{M} \mathrm{Na}_{2} \mathrm{~S}_{2.47}$ and $1 \mathrm{M} \mathrm{NaOH}$, simulating the operating conditions of a half-charged polysulfide-bromine redox flow battery. The catalyst activity increased in the following order: IF-WS $2<2 \mathrm{H}-\mathrm{WS}_{2}<$ ball milled $\mathrm{WS}_{2}$. We attempt to rationalize this trend on the basis of the morphological features observed ex-situ. The exchange current density of the ball milled $\mathrm{WS}_{2}$, at $\sim 0.012 \mathrm{~mA} \mathrm{~cm}^{-2}$, falls short of the estimated target by a factor of $\sim 60$ to 70 .

(C) 2013 The Electrochemical Society. [DOI: 10.1149/2.027306jes] All rights reserved.
\end{abstract}

Manuscript submitted November 7, 2012; revised manuscript received February 11, 2013. Published March 8, 2013.

There is an increasing need for energy storage on a large scale. ${ }^{1-4}$ This stems from a number of requirements: to improve power quality, improve economic efficiency and to enable more widespread use of renewable energy sources. At present, the most widely deployed means of storing energy on a large scale is hydroelectric power. However, the prerequisite for the construction of a new hydroelectric power station is the flooding of large areas of land. This is no longer permissible in Europe or North America due to social, political and environmental considerations. Consequently, new technologies are needed with the high efficiency and the low cost of hydroelectric power.

The polysulfide bromine redox flow battery could represent a viable solution for the storage of energy on a large scale. ${ }^{5-9}$ Through the following reaction, electrical energy is stored in chemical bonds:

$$
x \mathrm{Na}_{2} \mathrm{~S}_{x+1}+3 \mathrm{NaBr} \rightarrow(x+1) \mathrm{Na}_{2} \mathrm{~S}_{x}+\mathrm{NaBr}_{3}
$$

Upon charging, sodium tribromide is oxidized at the anode:

$$
3 \mathrm{NaBr} \rightarrow \mathrm{NaBr}_{3}+2 \mathrm{Na}^{+}+2 \mathrm{e}^{-}
$$

The sodium polysulfide species are reduced to lower polysulfide species at the cathode:

$$
x \mathrm{Na}_{2} \mathrm{~S}_{x+1}+2 \mathrm{Na}^{+}+2 \mathrm{e}^{-} \rightarrow(x+1) \mathrm{Na}_{2} \mathrm{~S}_{x}
$$

where $(1 \leq x \leq 4)$. Alternatively, only taking into consideration the most abundant species in solution (the other species are in equilibrium with these species), the polysulfide reaction can be depicted as: ${ }^{10}$

$$
\mathrm{S}_{4}^{2-}+4 \mathrm{H}_{2} \mathrm{O}+6 \mathrm{e}^{-} \rightleftharpoons 4 \mathrm{HS}^{-}+4 \mathrm{OH}^{-}
$$

The bromide and polysulfide reactions proceed in separate half cells, divided by an ion conducting membrane. Upon discharging the above reactions go into reverse.

The distinguishing feature of redox flow batteries in comparison to conventional, static batteries is that the electroactive species are stored in a separate tank..$^{11,12}$ Conversely, in a static battery, these always remain within the actual cell. This means that the total energy stored in a redox flow battery system is independent of its power rating. The total energy capacity is a function of the size of the electrolyte storage tank. Consequently, in redox flow batteries, economies of scale come into place when large amounts of energy need to be stored.

One of the chief advantages of the $\mathrm{S}_{x}^{2-}-\mathrm{Br}$ redox flow battery, relative to other redox flow batteries is that both $\mathrm{S}$ and $\mathrm{Br}$ are cheap and

\footnotetext{
${ }^{*}$ Electrochemical Society Active Member.

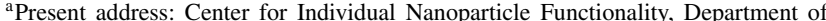
Physics, Technical University of Denmark (DTU), Kongens Lyngby DK 2800, Denmark

${ }^{z}$ Email: ifan@fysik.dtu.dk
}

abundant. Polysulfide species, $\mathrm{S}_{x}^{2-}$, have a high solubility in alkaline solutions, ${ }^{13}$ which gives the $\mathrm{Na}_{2} \mathrm{~S}_{x}$ electrolyte a favorable energy density in comparison to some other aqueous electrolytes. Nonetheless, the toxicity of the electrolyte in the Br half cell could be of some concern: when the $\mathrm{Br}$ electrolyte is in its charged state, the $\mathrm{Br}_{3}^{-}$anion will dissociate slightly to form $\mathrm{Br}_{2} \cdot{ }^{14}$

In order to evaluate the viability of the polysulfide bromine redox flow battery for large scale energy storage, two recent studies have employed numerical models. The first of these, by Denholm and Kulcinski, ${ }^{16}$ estimates the "life cycle losses" of polysulfide bromine redox flow batteries, vanadium redox flow batteries, hydroelectric power stations and compressed air energy storage. Not only did they take into account the losses incurred directly by the electrical conversion efficiency, but also the indirect energy losses. These indirect losses were those incurred by construction, operations and maintenance, and in the case of compressed air energy storage, from the fuel and its delivery. According to their analysis, the overall life cycle efficiency is highest for hydroelectric power and vanadium redox flow batteries, at $\sim 73 \%$. In comparison, the polysulfide bromine redox flow batteries and compressed air energy storage were estimated to have an efficiency of $\sim 65 \%$. Although the energy conversion efficiency of compressed air systems is high, their use of fossil fuels markedly increases the effective energy input. In the case of the $S_{x}^{2-}$-Br system, the majority of the energy losses seem to be caused by the low electricity conversion efficiency. Nevertheless, an increase in the electrical conversion efficiency from $65 \%$ to $75 \%$ would provide it with an overall efficiency equal to that of hydroelectric power. ${ }^{16}$

The key to improving the efficiency of the polysulfide bromine redox flow battery can be found in a recent study by Scamman et al. ${ }^{17,18}$ They performed numerical simulations to evaluate the overall cost effectiveness of the polysulfide-bromide redox flow battery. In brief, Scamman et al.'s investigation predicted that Regenesys' polysulfide-bromine redox flow battery would make a net economic loss. ${ }^{18}$ However, they also envisaged that the system would become profitable if an improvement was made to the kinetics of the system by increasing the rate constants of both half cells to $10^{-5} \mathrm{~ms}^{-1}$. Improved kinetics would result in a lower volume of cells and electrolyte, decreased energy losses during charging and discharging and a higher power density.

Since the rate constant for the polysulfide reaction is much lower than that of the bromide reaction, there is much more room for improvement in the kinetics of the polysulfide reaction. Arguably, the best way to achieve this would be to optimize the catalysis of the polysulfide half cell. Based on the rate constants stated above, this would require an exchange current density of $\sim 0.2 \mathrm{~A} \mathrm{~cm}^{-2}$ geometric surface area. ${ }^{19}$ In a redox flow battery, the electrodes are likely to 
be three dimensional, and the catalysts would be dispersed on a high surface area, conducting support such as C-black. ${ }^{9}$ This signifies that the true catalyst surface area should be appreciably higher than the 2D geometric surface area. For example, in a state of the art polymer electrolyte membrane fuel cell, the true microscopic surface area of its Pt catalysts is 200 to 320 times greater than the 2D geometric surface area. ${ }^{20}$ Assuming that equivalent degrees of dispersion are achievable with the electrocatalysts of a $\mathrm{S}_{x}^{2-}-\mathrm{Br}$ redox flow battery, the exchange current density required to achieve Scamman et al.'s targets would be $\sim 0.7$ to $1 \mathrm{~mA} \mathrm{~cm}^{-2}$ true microscopic surface area.

There are numerous experimental studies which suggest that Scamman et al.'s proposed improvements to the kinetics of the polysulfide bromine battery could be feasible. For instance, Zhang and co-workers showed that a polysulfide bromine redox flow battery with transition metal or metal sulfide catalysts at its electrodes had an improved efficiency over the same system with electrodes made entirely out of carbon. ${ }^{7,9}$ Moreover, there are several examples in the literature where the kinetics of polysulfide reduction and oxidation have been accelerated significantly through judicious use of electrode materials. ${ }^{7,8,21-27}$ However, very few, if any studies, have aimed to develop structureactivity relationships for electrocatalysts of polysulfide reduction and oxidation in particulate form.

Herein, we investigate the properties of several different forms of $\mathrm{WS}_{2}$ for polysulfide reduction and oxidation. Although bulk $\mathrm{WS}_{2}$ has not been studied previously for this reaction, several studies have reported that $\mathrm{MoS}_{2}$, which has a very similar chemistry to $\mathrm{WS}_{2}$, is a highly active catalyst for polysulfide reduction and oxidation. $^{23,24,28}$ Allen and Hickling investigated a W electrode for polysulfide oxidation; ${ }^{29}$ even though its bulk composition was metallic, its surface composition was likely to be a $\mathrm{WS}_{\mathrm{x}}$ phase (most metal surfaces have a tendency to form sulfide phases when exposed to sulfide containing electrolytes). ${ }^{21,27,30}$ Notably, the reduction of polysulfide occurs in nature via enzymes containing $\mathrm{W} ;^{31}$ this could suggest that electrocatalysts based on W could also hold promise for man-made applications. Finally, the catalytic properties of layered transition metal sulfides have been studied extensively. ${ }^{32-36}$ Previous investigations of these catalysts have focused primarily on (non-electrochemical) catalytic applications in the petrochemical industry, ${ }^{32,33,37}$ and also more recently for the electrochemical or photoelectrochemical evolution of hydrogen. ${ }^{34-36,38-42}$ They have shown how it is possible to tailor the surface chemistry of these materials toward high catalytic activity. Consequently, capitalizing upon this knowledge base should enable the optimisation of layered transition metal sulfides for polysulfide reduction and oxidation.

$\mathrm{MoS}_{2}$ and $\mathrm{WS}_{2}$ take on an anisotropic layered structure, known as the " $2 \mathrm{H}$-polytype", henceforth referred to as $2 \mathrm{H}-\mathrm{MoS}_{2}$ or $2 \mathrm{H}-\mathrm{WS}_{2}{ }^{43}$ The hexagonal arrangements within each layer are similar to those of graphite. Also, similar to graphite, the layers are held together by weak Van der Waal forces, which allow the sulfides to be used as a solid state lubricant. ${ }^{44}$

Fundamental investigations have afforded a deep understanding of the factors that govern the activity of these layered metal sulfide catalysts, enabling the improvement of their performance in large scale applications. ${ }^{32,34,35,37,45-48}$ Several studies have reported that the basal plane of these structures is inert, whereas the catalytically sites are located on the edge planes. ${ }^{46,49-51}$ This was clearly demonstrated by Jaramillo et al., who showed that the electrocatalytic activity of nanostructured $\mathrm{MoS}_{2}$ for hydrogen evolution was directly proportional to the length of its edge planes. ${ }^{34}$

In this work, we aim to determine whether the activity of metal sulfides can also be tailored for polysulfide reduction and oxidation. We shall achieve this by studying the properties of $\mathrm{WS}_{2}$ in particulate form. The pronounced structure dependence of the catalytic properties of $\mathrm{WS}_{2}$ make it particularly amenable to such investigations. Moreover, changes to the structure can be characterized easily using ex-situ microstructural characterization techniques such as high resolution transmission electron microscopy (HR-TEM) and X-ray diffraction (XRD).
Our work compares two nanostructured variants of $\mathrm{WS}_{2}$ in comparison to micron-sized particles of $2 \mathrm{H}-\mathrm{WS}_{2}$. In the first approach, edge planes and other defects are introduced into the $2 \mathrm{H}-\mathrm{WS}_{2}$ through the process of ball milling. In the second approach, we investigate a form of $\mathrm{WS}_{2}$ which has very few edge planes: inorganic fullerene-like $\mathrm{WS}_{2}\left(\mathrm{IF}-\mathrm{WS}_{2}\right) .{ }^{52}$ Both these forms of metal sulfides have previously been investigated as gas phase heterogeneous catalysts, where they showed promising activity. ${ }^{53-57}$ Moreover, a recent investigation also showed that doped nanotubes of $\mathrm{WS}_{2}$ can efficiently photodecompose organics. ${ }^{58}$ However, to the best of our knowledge, they have not been investigated for their electrocatalytic properties.

\section{Experimental}

Microstructural characterization.-X-ray diffraction.-X-ray diffraction (XRD) techniques were used for phase identification and the determination of crystallite size. A Phillips Vertical Diffractometer, model PW1050 was used, with the Bragg-Bretano geometry. This utilized $\mathrm{Cu} \mathrm{K} \mathrm{K}_{\alpha}$ radiation (with wavelength, $\lambda=1.5418 \AA$ ), a single bounce carbon monochromator, a $0.5 \mathrm{~mm}$ divergence slit, a $0.2 \mathrm{~mm}$ receiving slit, a $0.5 \mathrm{~mm}$ anti-scatter slit, a dwell time of $30 \mathrm{~s}$ and a step size of $0.02 \mathrm{~s}$. The powdered samples were placed on an oriented $\mathrm{Si}$ wafer for analysis.

From the peak width, it is possible to determine the crystallite size and microstrain in the crystal structure, although sometimes these two effects may be convoluted. ${ }^{59}$ The crystallite size was estimated from the peak width using the Debye-Scherrer equation:

$$
L_{h k l}=\frac{\lambda}{\beta_{h k l} \cos \theta_{h k l}}
$$

where $L_{h k l}$ is the length of the crystallite perpendicular to the $(h k l)$ crystallographic plane, $\beta_{h k l}$ is the integral breadth of the peak, $\theta_{h k l}$ is the peak position and $\lambda$ is the wavelength of the incident radiation. In order to estimate microstrain (i.e. inhomogenity in the lattice spacing) the following equation was used:

$$
\varepsilon_{h k l}=\frac{\beta_{h k l}}{4 \tan \theta_{h k l}}
$$

where $\varepsilon_{h k l}$ is the microstrain. The values of $\beta_{h k l}$ were corrected for instrumental broadening by measuring a calibration sample of $10 \mathrm{wt} \%$ silicon powder and $90 \mathrm{wt} \% \mathrm{WS}_{2}$ ball milled for 24 hours, using the method given by Langford et al. ${ }^{60}$

Surface area by gas adsorption.- - the surface area was determined using the Brunauer, Emmett and Teller (BET) method. This was achieved using a Micromeritics Tristar 3000 Instrument, using $\mathrm{N}_{2}$ as an adsorbent at $77.3 \mathrm{~K}$. Each catalyst powder was weighed so that its total BET surface area would come to the recommended amount of 5 to $10 \mathrm{~m}^{2}{ }^{61}$ Prior to the physical gas adsorption measurements, the samples were degassed overnight in a vacuum oven at $90^{\circ} \mathrm{C}$ at $1 \mathrm{mbar}$ total pressure. The decrease in mass as a result of the degassing procedure was always below $0.5 \%$.

Electron microscopy.- the scanning electron microscopy (SEM) images were taken in a field emission gun SEM JEOL-6340F, in secondary electron imaging (SEI) mode at an acceleration voltage of $5.0 \mathrm{kV}$.

A FEI Tecnai F20 microscope was used at an accelerating voltage of $200 \mathrm{kV}$. The catalyst powders were first dispersed in acetone for five minutes using an ultrasonic probe, and then dropped onto holey carbon $\mathrm{Cu}$ TEM grids. The TEM grids were supplied by Agar Scientific. Images taken in high resolution mode shall be designated as HRTEM images, whereas lower resolution images are designated as TEM images.

Catalysts.-inorganic fullerene like $\mathrm{WS}_{2}\left(\mathrm{IF}-\mathrm{WS}_{2}\right)$ was supplied by NanoMaterials Ltd, courtesy of Reshef Tenne. The synthesis of the $\mathrm{IF}-\mathrm{WS}_{2}$ is described by Feldman et al., ${ }^{62}$ and involves the reaction of WO $_{\mathrm{x}}$ nanoparticles with $\mathrm{H}_{2}$ and $\mathrm{H}_{2} \mathrm{~S}$ at elevated temperatures. 
The $2 \mathrm{H}-\mathrm{WS}_{2}(99.8 \%$ ) was supplied by Alfa Aesar. The ball milling experiments were carried out using a Spex 8000 vibratory mill. A custom made, hardened steel vial was used for the grinding. Prior to each experiment, the mill was cleaned in isopropyl alcohol using an ultrasonic probe. For each experiment, $7.30 \mathrm{~g}$ of material was placed inside the mill, along with $2 \times 1 / 2$ inch and $4 \times 1 / 4$ inch hardened steel balls. The powder occupied approximately $20 \%$ of the internal volume of the vial, as recommended by the mill's manufacturer. ${ }^{63}$ The vial was closed using a screw top lid, and sealed using a Viton O-ring. Before the milling commenced, the mill was degassed and back filled with $\mathrm{Ar}$ (at a pressure of 2 bar) at least 6 times via a ball valve. A piece of filter paper was placed between the ball valve and the pipe leading to the main body of the vial in order to prevent the powder from being evacuated from the vial. After milling, the sample was left to cool, before being opened to air and then transferred to a vacuum desiccator.

Electrochemical measurements. - the water was purified using a Millipore water system, where the resistivity of the water was measured to be greater than $18 \mathrm{M} \Omega \mathrm{cm}$. All electrochemical glassware was washed and sonicated in this water, prior to usage.

$\mathrm{Na}_{2} \mathrm{~S} .9 \mathrm{H}_{2} \mathrm{O}$ (ACS Reagent, >98\%), powdered S (99.98\%), $\mathrm{NaOH}$ (>97\%), $\mathrm{KCl}(99.5 \%$ to $100.5 \%)$ and paraffin wax were all supplied by Sigma Aldrich. Isopropyl alcohol (>99.5\%) and acetone (>99\%) were supplied by Fisher Scientific. Acetylene black (99.99\%) was supplied by Alfa Aesar.

The electrolyte was prepared as follows: the $\mathrm{NaOH}$ was dissolved in water in a flask placed on a magnetic heater/stirrer and deaerated for 30 minutes by bubbling it with Ar. An overpressure of Ar was maintained at all times. The $\mathrm{Na}_{2} \mathrm{~S} .9 \mathrm{H}_{2} \mathrm{O}$ was then dissolved in the deaerated $\mathrm{NaOH}$ solution at $40^{\circ} \mathrm{C}$. Once the $\mathrm{Na}_{2} \mathrm{~S} .9 \mathrm{H}_{2} \mathrm{O}$ had completely dissolved, the $\mathrm{S}$ was added and stirred until it had also dissolved. The solution was made up to the required volume with de-aerated water in a volumetric flask.

The catalysts were immobilized on the electrode using the "sticky carbon" method ${ }^{64,65}$ This sticky carbon composite was made of a mixture of $35 \mathrm{wt} \%$ acetylene black and $65 \mathrm{wt} \%$ paraffin wax. The working electrode body was supplied by BioAnalytical Systems, model MF-2010. It was made from chlorotrifluoroethylene (CTFE), and incorporated an empty inset, $4 \mathrm{~mm}$ in diameter, $3 \mathrm{~mm}$ deep. A heat gun was then used to raise the temperature of the wax to around $50^{\circ} \mathrm{C}$, so that the composite could be pressed further into place, albeit protruding out of the inset slightly. The surface of the electrode was then rubbed against a clean sheet of weighing paper, until it was smooth and planar.

A small amount of catalyst $(\sim 0.2 \mathrm{mg})$ was then dispersed using an analytical sieve onto a glass optical microscopy slide. The electrode was weighed on an analytical balance, before being pressed lightly against the catalyst. The catalyst loaded electrode was then reweighed to determine the amount of catalyst loaded on the electrode. The electrode was then transferred to the electrochemical cell.

All electrochemical measurements were controlled using a a PGSTAT 30 from Autolab. All impedance spectroscopy measurements were taken from $1 \mathrm{M} \mathrm{Hz}$ to $0.1 \mathrm{~Hz}$, with a peak to peak amplitude of $10 \mathrm{mV}$. The impedance spectra were fitted using Autolab's FRA software.

A two compartment, three electrode cell was used. A built in water jacket was used to maintain the cell at $35^{\circ} \mathrm{C}$; this is the operating temperature of the polysulfide bromine redox flow battery. ${ }^{17,26}$

All experiments were carried out under an inert, purified atmosphere of Ar, with a slight overpressure. The electrolyte was bubbled with Ar prior to the commencement of the experiments, and blanketed during the course of the experiment.

A Pt mesh of about $2 \mathrm{~cm}^{2}$ in geometrical surface area, was used as a counter electrode. The reference was a $3.5 \mathrm{M} \mathrm{KCl} /$ calomel electrode. All potentials were corrected so that they correspond to that of a saturated calomel electrode (SCE) at $25^{\circ} \mathrm{C}^{66}$ The reference electrode was placed in a flask containing $3.5 \mathrm{M} \mathrm{KCl}$, connected via an electrolytic bridge to the Luggin capillary.
An auxiliary 'high frequency shunt' was applied to the reference electrode, as described by Mansfeld et al. ${ }^{67}$ This comprised a Pt wire, whose tip coincided with the tip of the Luggin capillary. The wire was connected to the reference electrode via a $1 \mathrm{nF}$ capacitor.

Electrochemical characterization protocol.-Each catalyst was subjected to exactly the same electrochemical measurement protocol, in order to ensure adequate reproducibility. This can be described as follows: (a) The working electrode was placed into the cell. (b) The electrolyte was first purged with purified Ar for 45 minutes, and following this the Ar was blanketed over the surface of the electrolyte for a further 15 minutes. (c) The working electrode was repeatedly cycled potentiodynamically for one hour at $10 \mathrm{mVs}^{-1}$. Each scan proceeded in the following order: $\eta=0 \mathrm{~V} \rightarrow-0.27 \mathrm{~V} \rightarrow+0.22 \mathrm{~V}$ $\rightarrow 0 \mathrm{~V}$. (d) The potentiostatic steady state current measurement then commenced, proceeding in the following order: $\eta \sim-0.275 \mathrm{~V} \rightarrow$ $\sim+0.23 \mathrm{~V}$, increasing in $10 \mathrm{mV}$ intervals. The current was measured using a chronoamperometric technique, for $50 \mathrm{~s}$ at each potential (apart from the intial potential, where it was held for $100 \mathrm{~s}$ ). The steady state current was evaluated after $50 \mathrm{~s}$, immediately before the electrode was stepped to the next potential. (e) The potentiostatic measurement was also interspersed with impedance spectroscopy measurements at selected potentials.

\section{Results}

Microstructural characterization.- The X-ray diffraction traces of the various $\mathrm{WS}_{2}$ samples are shown on Figure 1. The traces have been plotted on a logarithmic scale; this scale was chosen simply because the (002) reflection is so much more intense than the other reflections that otherwise it would be difficult to view the smaller peaks, especially in the case of the $2 \mathrm{H}-\mathrm{WS}_{2}$. The predominance of the (002) reflection is a refelction of the anisotropic nature of the $2 \mathrm{H}-\mathrm{WS}_{2}$ material. Clearly, all the traces correspond quite closely to the reference pattern for $2 \mathrm{H}-\mathrm{WS}_{2}$. With increased milling time, the peaks become significantly broader, which (apart from instrumental broadening) could be either attributed to a decrease in crystallite size or increase in microstrain (as described in the Experimental section). In principle, these effects can be deconvoluted using Williamson Hall plots. ${ }^{68,69}$ However, since the peaks on the XRD traces are broad and convoluted, it was not possible to converge to a meaningful fit using this type of analysis.

Nevertheless, Table I provides a rough approximation of the crystallite size and extent of microstrain, through analysis of the (002) peak, centered at around $14^{\circ}$. The integral value of the peak breadth, $\beta_{(002)}$, was evaluated using a Lorentzian fit. Using equation 5 and

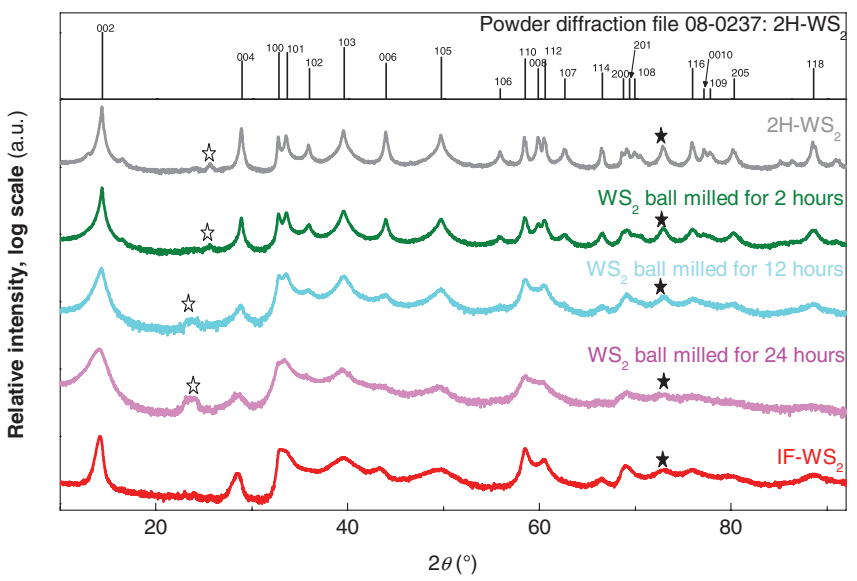

Figure 1. X-ray diffraction traces of $\mathrm{WS}_{2}$ based electrocatalyst powders. Starred peaks denote those that are not present in powder diffraction file 08-0237: $\star$ denotes an unknown peak, $\star$ denotes the peak attributed by Zhu et al. to the (203) reflection of $2 \mathrm{H}-\mathrm{WS}_{2} .{ }^{114}$ The relative intensities are shown on a logarithmic scale, with each trace offset vertically from the other. 
Table I. Analysis of (002) peak broadening in $\mathrm{WS}_{2}$ samples, from XRD results.

\begin{tabular}{|c|c|c|c|c|c|}
\hline & $2 \mathrm{H}-\mathrm{WS}_{2}$ & $\begin{array}{l}\mathrm{WS}_{2} \text { ball milled } \\
\text { for } 2 \text { hours }\end{array}$ & $\begin{array}{l}\mathrm{WS}_{2} \text { ball milled } \\
\text { for } 12 \text { hours }\end{array}$ & $\begin{array}{l}\mathrm{WS}_{2} \text { ball milled } \\
\text { for } 24 \text { hours }\end{array}$ & $\mathrm{IF}-\mathrm{WS}_{2}$ \\
\hline$\beta_{(002)}\left({ }^{\circ}\right)$ & 0.1 & 0.2 & 1.3 & 2.2 & 0.7 \\
\hline Minimum crystallite size (nm) & 79 & 38 & 7 & 4 & 14 \\
\hline Maximum microstrain & $0.4 \%$ & $0.8 \%$ & $4.7 \%$ & $7.9 \%$ & $2.3 \%$ \\
\hline
\end{tabular}

assuming that the broadening of the (002) peaks is entirely due to decreased crystallite size, we estimate the lowest possible value of the average crystallite size. Conversely, by using equation 6 and assuming that the broadening is entirely attributable to microstrain, we estimate the maximum degree of microstrain. The data in Table I show that the milling brings about a large increase in microstrain or decrease in crystallite size, which develops further with milling time. There are some minor shifts in the peak positions between the different samples, suggesting a change in the size of the unit cell.

There is a significant unidentified peak on the $\mathrm{WS}_{2}$ samples that were milled for 12 and 24 hours, centered at $\sim 24^{\circ}$. Most probably this is an artifact of the milling process which resulted in the formation of a second phase. This could either be due to contamination from the balls or the vials, or otherwise the segregation of a separate phase within the $\mathrm{WS}_{2}$. However, its intensity is still only $\sim 5 \%$ of the $(002)$ peak, and given that there are no other unidentified peaks of significant magnitude, the concentration of this second phase is probably low. There are some small additional peaks on the traces shown on Figure 1 (e.g. at $\sim 27^{\circ}$ on the unmilled $2 \mathrm{H}-\mathrm{WS}_{2}$ and the sample that was milled for 2 hours); however, bearing in mind the logarithmic scale, their intensity is negligible, and comparable to the background noise.

Electron microscopy.-FEG-SEM, TEM and HR-TEM images of the $2 \mathrm{H}-\mathrm{WS}_{2}$ particles are shown on Figures 2-4. Figure 5 shows FEGSEM images of the $\mathrm{WS}_{2}$ milled for 24 hours. Based upon these images, there is a marked difference between the milled and unmilled $2 \mathrm{H}-\mathrm{WS}_{2}$. Conversely, the different milled samples (not shown) are largely indistinguishable from each other. The milling process has resulted in a roughened microstructure, and the particles have lost their plateletlike morphology. It would be difficult to specify the dimensions of the particles, as they are of such an ill-defined shape and distribution that it is meaningless to distinguish an individual particle from the agglomerated mass to which it is attached. The agglomerates themselves are also fairly polydisperse, their size ranging from $\sim 100 \mathrm{~nm}$ to $\sim 20 \mu \mathrm{m}$.

The HR-TEM images shown on Figure 6 and Figure 7 provide further evidence of the effect of ball milling on the microstructure of $\mathrm{WS}_{2}$. The HR-TEM images of the $\mathrm{WS}_{2}$ ball milled for 2 hours are clearly distinguishable from those of the as received $2 \mathrm{H}-\mathrm{WS}_{2}$ The particles are no longer shaped like platelets, and the edges are particularly distorted. However, it is still possible to observe some ordered, uninterrupted lattice fringes of the $(00 l)$ plane that span tens of nanometres. This is similar in order of magnitude to the minimum
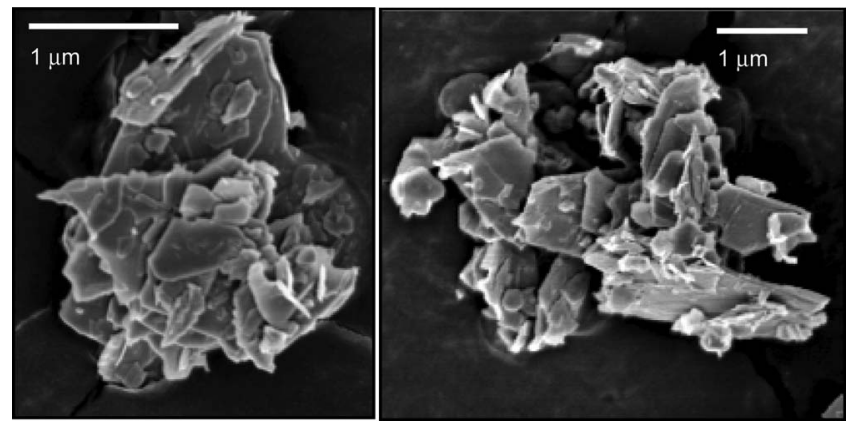

Figure 2. FEG-SEM images showing typical particles of $2 \mathrm{H}-\mathrm{WS}_{2}$ on carbon backing tape.

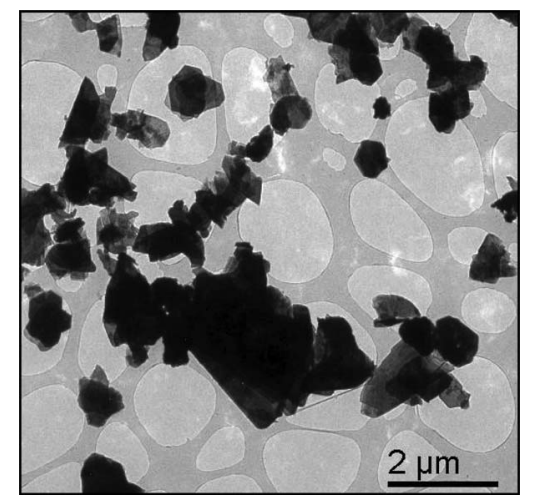

Figure 3. TEM images of the $2 \mathrm{H}-\mathrm{WS}_{2}$ particles, supported on a holey carbon film.

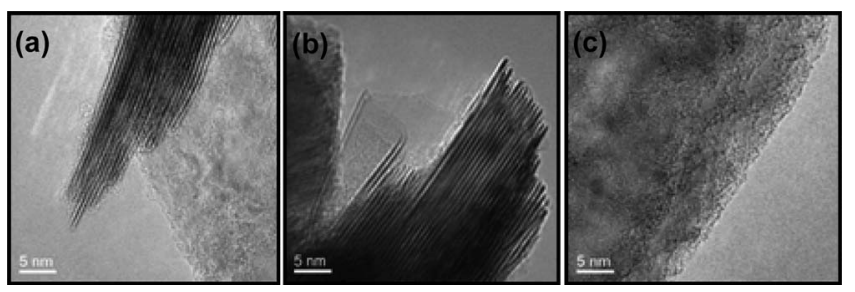

Figure 4. HR-TEM images of $2 \mathrm{H}-\mathrm{WS}_{2}$, (a) and (b) with basal plane lying perpendicular to the electron beam, and (c) with edge planes $(h k 0)$ lying perpendicular to the electron beam.
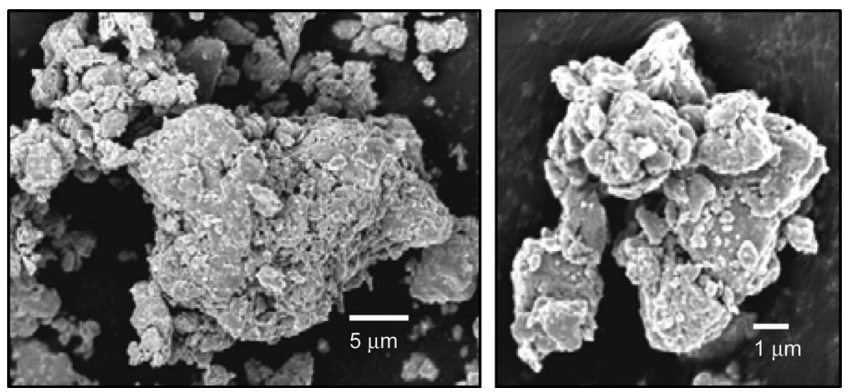

Figure 5. FEG-SEM images showing typical particles of $\mathrm{WS}_{2}$ ball milled for 24 hours, on carbon backing tape.
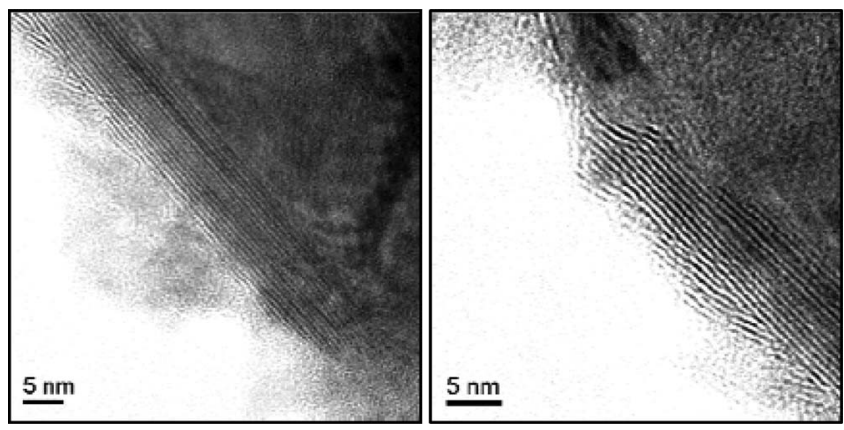

Figure 6. HR-TEM images of the $\mathrm{WS}_{2}$ ball milled for 2 hours, supported on a holey carbon film. 


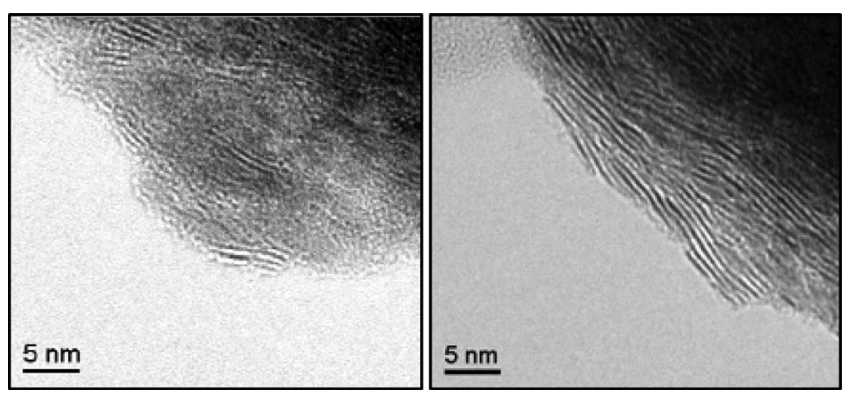

Figure 7. HR-TEM images of the $\mathrm{WS}_{2}$ ball milled for 24 hours, supported on a holey carbon film.

average crystallite size which was estimated in Table I from the (002) peak in the XRD data. Notably, Kouzu et al.'s HR-TEM images of ball milled $2 \mathrm{H}-\mathrm{MoS}_{2}$ resemble those shown here. ${ }^{55}$

On the basis of the HR-TEM images, the $\mathrm{WS}_{2}$ that was milled for 24 hours, shown on Figure 7, seems more distorted than the sample that was milled for 2 hours, shown on Figure 6. Although it is still possible to see the lattice fringes from the $(00 l)$ reflection on the $\mathrm{WS}_{2}$ ball milled for 24 hours, they are much distorted and there many dislocations present. Moreover, the extent of each ordered domain does not span more than about 4-5 nm, which is similar to the minimum crystallite size predicted from the XRD data, $4 \mathrm{~nm}$ (c.f. Table I).

The typical size and morphology of the IF-WS $\mathrm{W}_{2}$ particles are depicted on the SEM and TEM images shown on Figures 8-10. These images are similar to those previously taken by Tenne and co-workers of the same material. ${ }^{62}$ The particles are somewhat agglomerated, but also fairly homogeneous. They are shaped like deformed, ellipsoid spheres, about $100-150 \mathrm{~nm}$ in diameter.

The HR-TEM images of the IF-WS 2 , shown on Figure 10, clearly show the "nest-like" structure of the particles. ${ }^{70}$ As expected, the surfaces almost completely consist of the basal $(00 l)$ planes, which can clearly be seen from the lattice fringes. The particles are angular and faceted, in contrast to the continuously curved shape of $\mathrm{C}$ based fullerenes. On a given facet, the basal planes are fairly linear, and it is not apparent that they have to accommodate much radial strain. They do appear to be some steps along the $(00 l)$ surfaces, along with some amorphous material, and it could be anticipated that these features

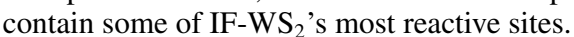

Given that the catalytically active sites of these materials are generally acknowledged to be the edge planes, ${ }^{46,49-51}$ it is worth considering the abundance of these sites on the different materials. Although TEM and XRD are not surface sensitive techniques, the information they provide can be correlated to the surface termination. ${ }^{71,51}$ The $2 \mathrm{H}$ $\mathrm{WS}_{2}$ forms anisotropic platelets, oriented along the (001) plane, with few edge planes, simply because the basal plane would have a much lower surface energy than the edges. ${ }^{72}$ Likewise, the closed nature of the IF-WS ${ }_{2}$ (as shown in the TEM images) means that they would have even fewer edge planes than the $2 \mathrm{H}-\mathrm{WS}_{2}$; indeed the driving force for their formation is the removal of the edge planes. ${ }^{73}$ On the other hand, the ball milling would introduce metastable facets and
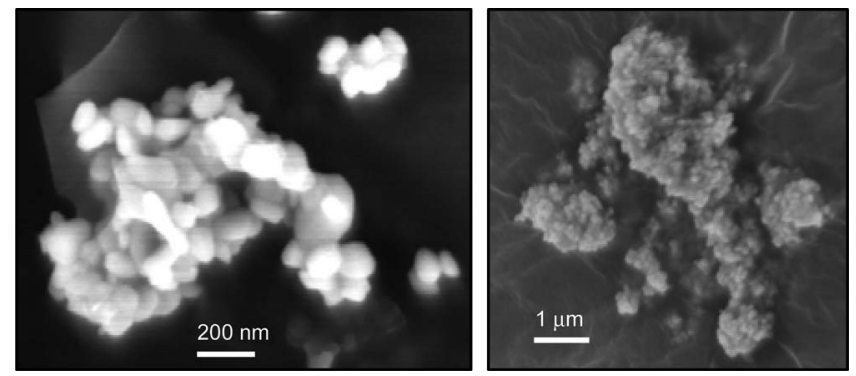

Figure 8. FEG-SEM images of IF-WS 2 , supported on a carbon backing tape

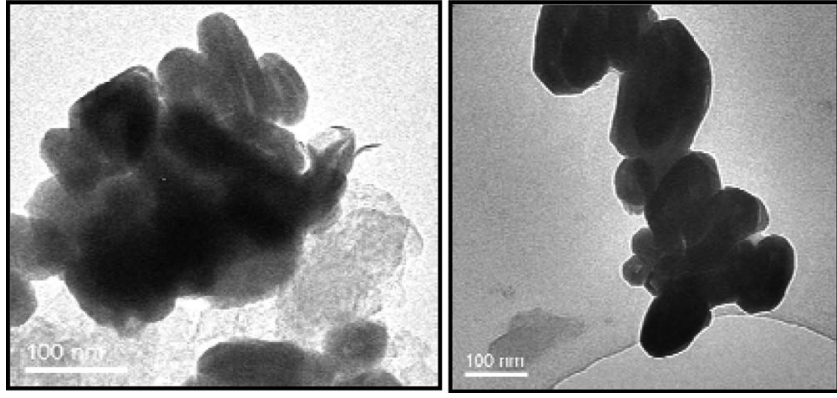

Figure 9. TEM images showing IF - $\mathrm{WS}_{2}$ particles, supported on a holey carbon film.

defects which would be less thermodynamically stable than the basal plane. This interpretation is consistent with the HR-TEM images and XRD analysis, which together suggest that the structure is structure of the ball milled $\mathrm{WS}_{2}$ is comprised of smaller crystallites, and contains many dislocations and stacking faults. It seems likely that at the surface these bulk defects would be manifested as defects such as edge planes or steps. ${ }^{51,71}$ The TEM images of the milled $\mathrm{WS}_{2}$ are qualititavely similar to those of recently reported "double-gyroid" $\mathrm{MoS}_{2}$, a catalyst engineered to have a high proportion of edge sites at its surface. ${ }^{74}$ In summary, it seems that the abundance of the edge planes and similar surface sites increases in the following order IF- $\mathrm{WS}_{2}<2 \mathrm{H}-$ $\mathrm{WS}_{2}<$ milled $\mathrm{WS}_{2}$.

EDX analysis. - In order to determine the elemental composition of the $\mathrm{WS}_{2}$ samples, SEM-based EDX analyzes were performed. One of the primary motivations for doing this was to determine whether milling procedure had introduced metallic impurities into the material through its interaction with the balls and vial.

Typical spectra of the $2 \mathrm{H}-\mathrm{WS}_{2}$, the $\mathrm{WS}_{2}$ milled for 24 hours, and the IF-WS $\mathrm{S}_{2}$ are shown on Figure 11. The spectra of the $2 \mathrm{H}-\mathrm{WS}_{2}$ and the IF-WS $\mathrm{W}_{2}$ are close to identical. W and $\mathrm{S}$ are the most prominent peaks, as expected from the XRD data. There are some additional peaks due to $\mathrm{Pt}, \mathrm{C}$ and $\mathrm{O}$. The $\mathrm{Pt}$ is from the conductive coating sputtered onto the surface of the catalysts to prevent charging. The $\mathrm{C}$ is probably due to the backing tape which was used to support the particles. The $\mathrm{O}$ peak is so small that it can be neglected.

The $\mathrm{WS}_{2}$ that was milled for 24 hours exhibits the same peaks as the other two samples, with the exception of Pt. The $\mathrm{S}$ peak is slightly diminished whereas the $\mathrm{O}$ peak has increased in magnitude. Notably, no other metallic elements were detected that could have been introduced from the hardened steel vial and balls of the ball mill, such as $\mathrm{Fe}, \mathrm{Cr}$ or Ni. However, it is possible that these elements are present in concentrations lower than $\sim 0.1 \%$, the limiting sensitivity of EDX. ${ }^{75}$

Surface area by gas adsorption.- The BET surface area of all the catalysts is relatively low, ranging between 2.3 and $6.2 \mathrm{~m}^{2} \mathrm{~g}^{-1}$, as summarized in Table II. The ball milling effects an initial increase in the surface area, but then passes through a maximum before decreasing again. These values seem reasonable: a very rough estimation can be made of the expected surface area of the IF-WS particles are $100 \mathrm{~nm}$ in diameter, completely spherical and have a
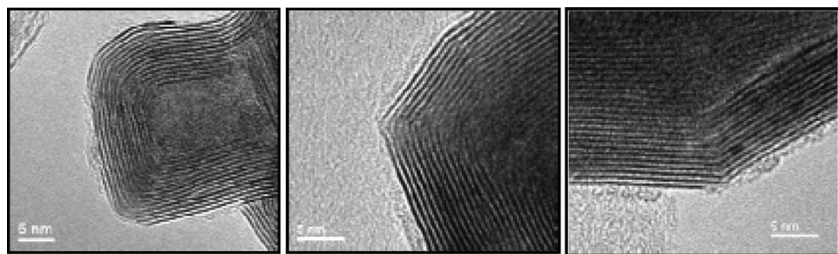

Figure 10. HR-TEM images of the IF-WS 2 particles. 


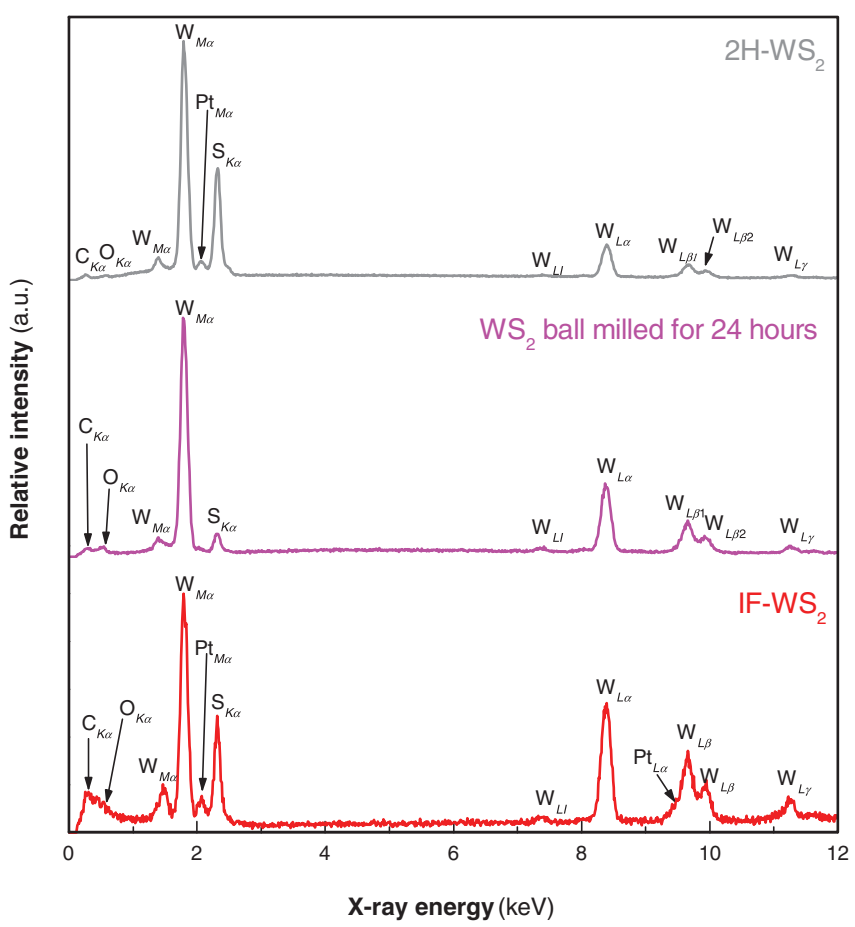

Figure 11. Typical EDX spectra of $2 \mathrm{H}-\mathrm{WS}_{2}, \mathrm{WS}_{2}$ ball milled for 24 hours and IF-WS 2 .

filled core with the theoretical density of $7.73 \mathrm{~g} \mathrm{~cm}^{-3}$, yields a value of $\sim 8 \mathrm{~m}^{2} \mathrm{~g}^{-1}$. Alternatively, by using the measured density of a pellet of IF-WS 2 , at $4.5 \mathrm{~g} \mathrm{~cm}^{-3}$ (which is presumably lower than the theoretical value as result of the hollow core $)^{76}$ the surface area is $\sim 13 \mathrm{~m}^{2} \mathrm{~g}^{-1}$.

Electrochemical characterization.- All of the electrodes tested, including the carbon substrate, and the Pt counter electrode reached the same potential, $-0.754 \mathrm{~V}$ with respect to an SCE, within a few minutes of immersion within the cell. This is consistent with reports in the literature, ${ }^{10,29,77,78}$ and suggests that this potential is the reversible Nernst potential for polysulfide reduction and oxidation. Moreover, we assume, unless otherwise specified that all voltammetric and potentiostatic dc currents are faradaic in nature, and are selective toward polysulfide reduction and oxidation. ${ }^{21-27,29,78}$

The initial activity of the different samples toward polysulfide reduction and oxidation is shown on Figure 12. The inset shows the response of the unmilled $2 \mathrm{H}-\mathrm{WS}_{2}$ in comparison to the blank sticky carbon substrate, demonstrating that they are clearly distinguishable from each other, except at high anodic overpotentials. In the main plot, the current densities have been normalized according to their BET surface area. It is evident that ball milling the $\mathrm{WS}_{2}$ samples considerably increases their activity for both polysulfide reduction and oxidation. The data also shows that there is an increase in activity with milling time, as the current densities increase in the following

Table II. Summary of BET surface area and analysis for $\mathrm{WS}_{\mathbf{2}}$ catalysts tested.

\begin{tabular}{lc} 
Catalyst & BET surface area $\left(\mathrm{m}^{2} / \mathrm{g}\right)$ \\
\hline $2 \mathrm{H}-\mathrm{WS}_{2}$ & $2.80 \pm 0.01$ \\
$\mathrm{WS}_{2}$ milled for 2 hours & $6.12 \pm 0.07$ \\
$\mathrm{WS}_{2}$ milled for 12 hours & $5.74 \pm 0.03$ \\
$\mathrm{WS}_{2}$ milled for 24 hours & $2.35 \pm 0.01$ \\
$\mathrm{IF}_{-} \mathrm{WS}_{2}$ & $6.23 \pm 0.08$
\end{tabular}

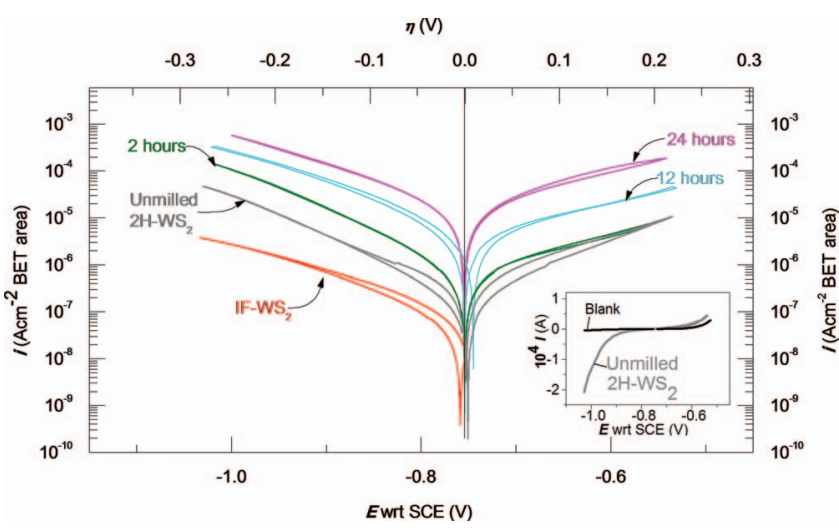

Figure 12. Initial potentiodynamic sweep of different $\mathrm{WS}_{2}$ samples. Normalized according to BET surface area. Taken in $1.8 \mathrm{M} \mathrm{Na}_{2} \mathrm{~S}_{2.47}$ and $1 \mathrm{M} \mathrm{NaOH}$ at $35^{\circ} \mathrm{C}$. The scan proceeded in the following order: $\eta=0 \mathrm{~V} \rightarrow-0.27 \mathrm{~V} \rightarrow$ $+0.22 \mathrm{~V} \rightarrow 0 \mathrm{~V}$; sweep rate: $10 \mathrm{mV} \cdot \mathrm{s}^{-1}$. The anodic response of the IF-WS has been omitted, as it was lower than that of the sticky carbon substrate. The inset shows the response of $0.16 \mathrm{mg}$ unmilled $2 \mathrm{H}-\mathrm{WS}_{2}$ in comparison to the blank substrate.

order: unmilled $2 \mathrm{H}-\mathrm{WS}_{2}<\mathrm{WS}_{2}$ milled for 2 hours $<\mathrm{WS}_{2}$ milled for 12 hours $<\mathrm{WS}_{2}$ milled for 24 hours.

It also appears that the IF-WS 2 shows a lower activity than the $2 \mathrm{H}$ $\mathrm{WS}_{2}$, especially at high cathodic overpotentials. The anodic response of the IF-WS $\mathrm{W}_{2}$ has been omitted from Figure 12 (as well as subsequent electrochemical data), as the catalyst loaded electrode was generally less active than the blank sticky carbon substrate.

The unmilled $2 \mathrm{H}-\mathrm{WS}_{2}$ and the milled $\mathrm{WS}_{2}$ show very little hysteresis between scans taken in the positive and negative directions, under cathodic polarization. This suggests that the current is faradaic in nature and approximates to its steady state value. The hysteresis is slightly more pronounced on the IF-WS $\mathrm{W}_{2}$, but only at low cathodic overpotentials. On all $\mathrm{WS}_{2}$ samples there is a limited degree of hysteresis at anodic overpotentials. This hysteresis could possibly be attributed due to an adsorption pseudocapacitance, reconstruction of the surface, or the formation of elemental S.

Figure 13 shows that after cycling the electrodes for one hour, the same general trends in activity persist as those for the first sweep. However, there is a notable decline in activity over this period for the $\mathrm{WS}_{2}$ that was ball milled for 24 hours. The cathodic current decreases by 15 to $20 \%$, whereas the anodic current drops by 40

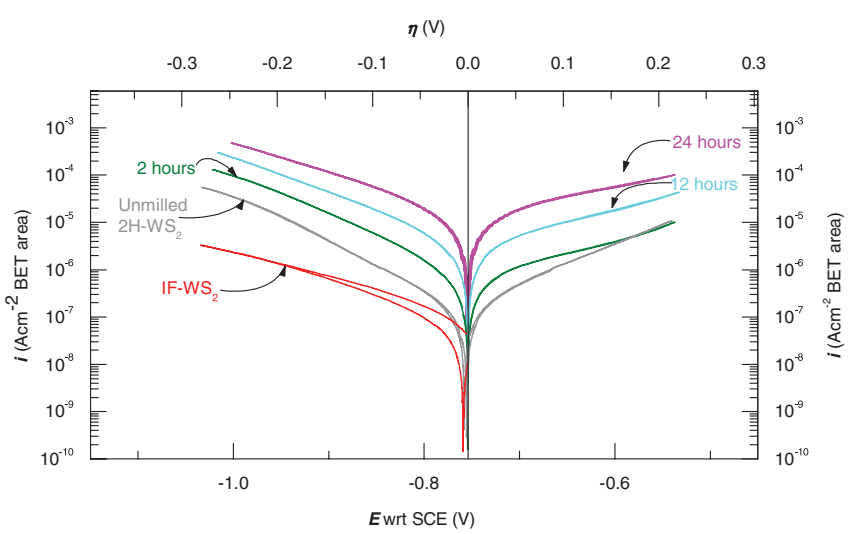

Figure 13. Potentiodynamic polarization response of different $\mathrm{WS}_{2}$ samples, after one hour of cycling, i.e. 32 cycles . Taken in $1.8 \mathrm{M} \mathrm{Na}_{2} \mathrm{~S}_{2.47}$ and $1 \mathrm{M} \mathrm{NaOH}$ at $35^{\circ} \mathrm{C}$. The scan proceeded in the following order: $\eta=0 \mathrm{~V} \rightarrow-0.27 \mathrm{~V}$ $\rightarrow+0.22 \mathrm{~V} \rightarrow 0 \mathrm{~V}$; sweep rate: $10 \mathrm{mV} \cdot \mathrm{s}^{-1}$. The anodic response of the IF-WS ${ }_{2}$ has been omitted, as it was lower than that of the sticky carbon substrate. 
Table III. Tafel parameters for different $\mathrm{WS}_{2}$ samples, from the potentiostatic data presented in Figure 14. The errors shown are the standard deviation in each fit.

\begin{tabular}{|c|c|c|c|c|}
\hline Catalyst & $\eta(\mathrm{V})$ & $10^{3} b\left(\mathrm{~V} \mathrm{decade}^{-1}\right)$ & $10^{6} i_{0}\left(\mathrm{~A} \mathrm{mg}^{-1}\right)$ & $10^{8} i_{0}\left(\mathrm{~A} \mathrm{~cm}^{-2} \mathrm{BET}\right.$ \\
\hline \multicolumn{5}{|l|}{ Upper cathodic region } \\
\hline Unmilled $2 \mathrm{H}-\mathrm{WS}_{2}$ & -0.273 to -0.154 & $148 \pm 5$ & $29 \pm 3$ & $103 \pm 12$ \\
\hline $\mathrm{WS}_{2}$ milled for 24 hours & -0.248 to -0.109 & $179 \pm 8$ & $436 \pm 9$ & $1850 \pm 40$ \\
\hline $\mathrm{IF}-\mathrm{WS}_{2}$ & -0.280 to -0.120 & $200 \pm 3$ & $9 \pm 3$ & $15 \pm 6$ \\
\hline \multicolumn{5}{|l|}{ Lower cathodic region } \\
\hline Unmilled $2 \mathrm{H}-\mathrm{WS}_{2}$ & -0.154 to -0.059 & $100 \pm 2$ & $9.3 \pm 0.5$ & $33 \pm 2$ \\
\hline $\mathrm{WS}_{2}$ milled for 24 hours & -0.109 to -0.055 & $128 \pm 5$ & $250 \pm 20$ & $1090 \pm 70$ \\
\hline IF-WS ${ }_{2}$ & -0.120 to -0.060 & $128 \pm 5$ & $4.1 \pm 0.2$ & $6.6 \pm 0.3$ \\
\hline \multicolumn{5}{|l|}{ Lower anodic region } \\
\hline $2 \mathrm{H}-\mathrm{WS}_{2}$ & +0.059 to +0.089 & $115 \pm 3$ & $5.5 \pm 0.2$ & $19.7 \pm 0.7$ \\
\hline $\mathrm{WS}_{2}$ milled for 24 hours & +0.053 to +0.106 & $210 \pm 8$ & $267 \pm 9$ & $1140 \pm 40$ \\
\hline \multicolumn{5}{|l|}{ Upper anodic region } \\
\hline $\mathrm{WS}_{2}$ milled for 24 hours & +0.106 to 0.217 & $370 \pm 20$ & $450 \pm 25$ & $1900 \pm 100$ \\
\hline
\end{tabular}

to $50 \%$. Conversely, the other samples retained their activity upon cycling, within a $\sim 5 \%$ margin.

The data presented thus far suggest that the microstructural and electrochemical characteristics of the samples milled for 2 hours and 12 hours seem to be intermediate between those of the unmilled sample $2 \mathrm{H}-\mathrm{WS}_{2}$ and the sample which was milled for 24 hours. Consequently, for the purpose of brevity, we shall focus on the unmilled sample and the sample that was milled for 24 hours, which shall henceforth be referred to as the milled $\mathrm{WS}_{2}$.

Following the potentiodynamic measurements, the steady state current was also measured potentiostatically. These data are shown on Figure 14. Neither the milled $\mathrm{WS}_{2}$ nor the IF-WS ${ }_{2}$ show a marked change in cathodic activity between the potentiodynamic and potentiostatic measurements. In contrast, the $2 \mathrm{H}-\mathrm{WS}_{2}$ exhibited a three-fold increase in activity toward polysulfide reduction when measured potetionstatically.

On the other hand, under anodic polarization the potentiostatic activity of the milled $\mathrm{WS}_{2}$ was up to $\sim 50 \%$ lower than the activity measured potentiodynamically. In order to investigate whether this anodic deactivation of the ball milled sample was due to mass transport induced passivation, the experiment was also carried out in the presence of a magnetic stirrer. However, the activity of the unstirred sample was identical to that of the stirred sample. This suggests that the polarization of the milled $\mathrm{WS}_{2}$ is not influenced by mass transport.

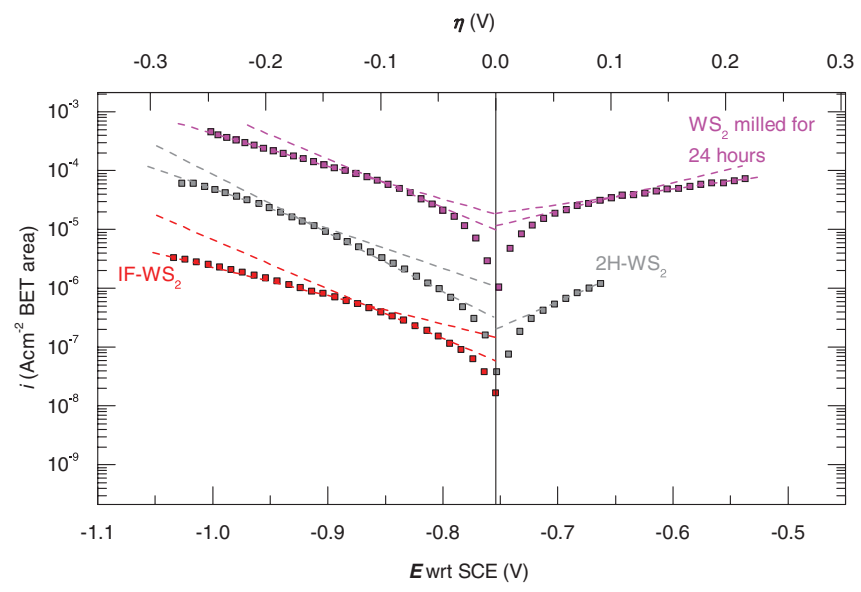

Figure 14. Potentiostatic steady state polarization response of $\mathrm{WS}_{2}$ ball milled for 24 hours, $2 \mathrm{H}-\mathrm{WS}_{2}$ and IF-WS 2 . Normalized according to BET surface area. Taken in $1.8 \mathrm{~mol} \mathrm{dm}^{-3} \mathrm{Na}_{2} \mathrm{~S}_{2.47}$ and $1 \mathrm{~mol} \mathrm{dm}^{-3} \mathrm{NaOH}$, at $35^{\circ} \mathrm{C}$ Measurements proceeded in the positive (anodic) direction. Squares show measured data, dashed lines show fit. The anodic response of the IF-WS 2 has been omitted, as it was lower than that of the sticky carbon substrate.
Table III summarizes the Tafel parameters evaluated from the potentiostatic steady state polarization data shown in Figure 14, fitted to the exponential approximation of the Butler-Volmer equation: ${ }^{79}$

$$
i_{\mathrm{SS}}=i_{0} 10^{ \pm \eta / b}
$$

where $i_{\mathrm{SS}}$ is the steady state current, $i_{0}$ is the exchange current density. $b$ is the Tafel slope, and $\eta$ is the overpotential. The exchange current densities varied somewhat between independent measurements of the same sample, with a standard deviation of up to $\sim 35 \%$. However, this error is not significant enough to affect the overall trends observed between the Figure 14 shows that there is some curvature in the Tafel slopes for all samples. As summarized in Table III, at low cathodic overpotentials, both the IF-WS 2 and the milled $\mathrm{WS}_{2}$ exhibited Tafel slopes of $\sim 130 \mathrm{mV}$ decade ${ }^{-1}$. At higher overpotentials, the IF-WS $\mathrm{W}_{2}$ and the milled $\mathrm{WS}_{2}$ sample exhibited apparent Tafel slopes of $\sim 180 \mathrm{mV} \mathrm{decade}^{-1}$ and $\sim 200 \mathrm{mV}$ decade $^{-1}$, respectively.

Under anodic polarization, the Tafel slopes of the milled $\mathrm{WS}_{2}$ were $\sim 210 \mathrm{mV} \mathrm{decade}{ }^{-1}$ at low overpotentials and $\sim 370 \mathrm{mV} \mathrm{decade}^{-1}$ at high anodic overpotentials. The latter value is exceptionally high, and suggests that the current is not controlled purely by electrochemical charge transfer kinetics (a kinetically controlled current would typically have a Tafel slope up to $\left.\sim 120 \mathrm{mV} \mathrm{decade}^{-1}\right){ }^{80}$

The Tafel slopes alone can provide no additional information to understand the factors controlling the apparent activity of these catalysts. Consequently, we used impedance spectroscopy was used to shed further light upon the underlying electrochemistry of these materials.

Impedance spectroscopy.- The same general features were present on the impedance spectra of all samples. However, for the purpose of brevity, we will focus the discussion here on the impedance spectra of the most active sample, the milled $\mathrm{WS}_{2}$.

Typical impedance spectra of the $\mathrm{WS}_{2}$ that was milled for 24 hours are shown on Figure 15 and Figure 16, taken under anodic and cathodic polarization, respectively. There are two peaks: at high frequencies, between 10 and $100 \mathrm{kHz}$, and at low frequencies, between 10 and $100 \mathrm{~Hz}$. Both relaxations are also clearly distinguishable from each other on the Nyquist plot, and are manifested as depressed, intersecting semicircles.

When fitting these data, the equivalent circuit shown on Figure 17 provided the best fit for all samples. Both relaxations in the impedance spectra can be modeled by parallel combinations of a resistance and a constant phase element, $R_{1}$ and $\mathrm{CPE}_{1}$ for the low frequency relaxation and $R_{2}$ and $\mathrm{CPE}_{2}$ for the high frequency relaxation. The fitting parameters for these spectra are summarized on Table IV.

With increasing cathodic overpotential, the low frequency intercept on the real axis, $Z^{\prime}$ decreases, as shown on Figure 15, due to the lowering of kinetic barriers as the system is drawn away from equilibrium. On the other hand, Figure 16 shows that under anodic 


\section{Table IV. Fitted parameters from impedance response of $\mathrm{WS}_{2}$ milled for 24 hours, in $1.8 \mathrm{M} \mathrm{Na}_{2} \mathrm{~S}_{2.47}$ and $1 \mathrm{M} \mathrm{NaOH}$, at $35^{\circ} \mathrm{C}$. The surface areas} were measured using the BET method.

\begin{tabular}{|c|c|c|c|c|c|c|c|c|c|}
\hline$\eta(\mathrm{V})$ & $\begin{array}{c}R_{\Omega} \\
\left(\Omega \cdot \mathrm{cm}^{2}\right)\end{array}$ & $\begin{array}{c}R_{1} \\
\left(\Omega \cdot \mathrm{cm}^{2}\right)\end{array}$ & $\begin{array}{c}10^{6} Q_{1} \\
\left(\mathrm{~F} \mathrm{~s}^{n-1} \mathrm{~cm}^{-2}\right)\end{array}$ & $n_{1}$ & $\begin{array}{c}10^{6} C_{1} \\
\left(\mathrm{~F} . \mathrm{cm}^{-2}\right)\end{array}$ & $\begin{array}{l}10^{-2} R_{2} \\
\left(\Omega . \mathrm{cm}^{2}\right)\end{array}$ & $\begin{array}{c}10^{8} Q_{2} \\
\left(\mathrm{~F} \mathrm{~s}^{n-1} \mathrm{~cm}^{-2}\right)\end{array}$ & $n_{2}$ & $\begin{array}{c}10^{8} C_{2} \\
\left(\mathrm{~F} . \mathrm{cm}^{-2}\right)\end{array}$ \\
\hline-0.256 & $49 \pm 1$ & $86 \pm 2$ & $151 \pm 8$ & $0.59 \pm 0.01$ & 7.5 & $0.96 \pm 0.02$ & $164 \pm 9$ & $0.63 \pm 0.01$ & 0.9 \\
\hline-0.211 & $65 \pm 1$ & $162 \pm 4$ & $106 \pm 10$ & $0.60 \pm 0.02$ & 7.4 & $1.14 \pm 0.04$ & $79 \pm 8$ & $0.73 \pm 0.02$ & 2.6 \\
\hline-0.168 & $68 \pm 1$ & $309 \pm 8$ & $78 \pm 8$ & $0.62 \pm 0.02$ & 8.3 & $1.71 \pm 0.06$ & $72 \pm 7$ & $0.74 \pm 0.02$ & 2.8 \\
\hline-0.142 & $66 \pm 1$ & $446 \pm 8$ & $74 \pm 6$ & $0.61 \pm 0.02$ & 8.6 & $2.0 \pm 0.1$ & $59 \pm 4$ & $0.75 \pm 0.01$ & 3.0 \\
\hline-0.104 & $68 \pm 1$ & $686 \pm 15$ & $64 \pm 5$ & $0.61 \pm 0.02$ & 8.7 & $2.7 \pm 0.1$ & $49 \pm 4$ & $0.76 \pm 0.01$ & 3.1 \\
\hline-0.076 & $76 \pm 2$ & $1000 \pm 30$ & $54 \pm 6$ & $0.62 \pm 0.02$ & 8.8 & $3.5 \pm 0.1$ & $43 \pm 5$ & $0.77 \pm 0.02$ & 3.0 \\
\hline-0.047 & $74 \pm 2$ & $1340 \pm 40$ & $49 \pm 5$ & $0.61 \pm 0.02$ & 8.5 & $4.3 \pm 0.2$ & $35 \pm 3$ & $0.78 \pm 0.02$ & 3.1 \\
\hline-0.009 & $65 \pm 1$ & $2030 \pm 40$ & $41 \pm 3$ & $0.63 \pm 0.02$ & 9.4 & $5.3 \pm 0.2$ & $34 \pm 2$ & $0.79 \pm 0.01$ & 3.5 \\
\hline 0.000 & $65 \pm 1$ & $2070 \pm 50$ & $40 \pm 3$ & $0.63 \pm 0.02$ & 9.2 & $5.4 \pm 0.2$ & $33 \pm 2$ & $0.79 \pm 0.01$ & 3.5 \\
\hline+0.040 & $67 \pm 1$ & $2180 \pm 50$ & $32 \pm 3$ & $0.62 \pm 0.02$ & 6.4 & $7.2 \pm 0.2$ & $23 \pm 2$ & $0.82 \pm 0.01$ & 3.3 \\
\hline+0.050 & $68 \pm 2$ & $2140 \pm 50$ & $31 \pm 3$ & $0.62 \pm 0.02$ & 5.7 & $7.7 \pm 0.2$ & $21 \pm 2$ & $0.83 \pm 0.01$ & 3.3 \\
\hline+0.089 & $69 \pm 1$ & $1910 \pm 50$ & $28 \pm 2$ & $0.60 \pm 0.02$ & 4.0 & $9.0 \pm 0.3$ & $15 \pm 1$ & $0.85 \pm 0.01$ & 3.1 \\
\hline+0.108 & $70 \pm 1$ & $1710 \pm 60$ & $28 \pm 3$ & $0.59 \pm 0.02$ & 3.6 & $9.8 \pm 0.4$ & $12 \pm 1$ & $0.87 \pm 0.01$ & 3.0 \\
\hline+0.118 & $72 \pm 1$ & $1650 \pm 60$ & $28 \pm 3$ & $0.59 \pm 0.03$ & 3.3 & $10.6 \pm 0.4$ & $11 \pm 1$ & $0.87 \pm 0.01$ & 2.9 \\
\hline+0.147 & $73 \pm 1$ & $1280 \pm 60$ & $36 \pm 4$ & $0.56 \pm 0.03$ & 3.3 & $10.9 \pm 0.4$ & $9 \pm 1$ & $0.89 \pm 0.01$ & 2.8 \\
\hline+0.186 & $76 \pm 2$ & $780 \pm 50$ & $68 \pm 8$ & $0.52 \pm 0.03$ & 4.4 & $10.6 \pm 0.4$ & $6 \pm 1$ & $0.91 \pm 0.01$ & 2.4 \\
\hline+0.216 & $75 \pm 2$ & $490 \pm 30$ & $150 \pm 20$ & $0.45 \pm 0.03$ & 6.5 & $9.2 \pm 0.3$ & $5 \pm 1$ & $0.93 \pm 0.01$ & 2.2 \\
\hline
\end{tabular}

polarization, the low frequency intercept on the real axis is virtually unchanged between the $\eta=0 \mathrm{~V}$ and $\eta=+0.108 \mathrm{~V}$.

This anomalous behavior can be traced back to the high frequency relaxation, due to $\mathrm{R}_{2}$ and $\mathrm{CPE}_{2}$. The depressed semicircle corresponding to this relaxation actually becomes more prominent as the electrode is polarized in the positive direction. It seems likely that the
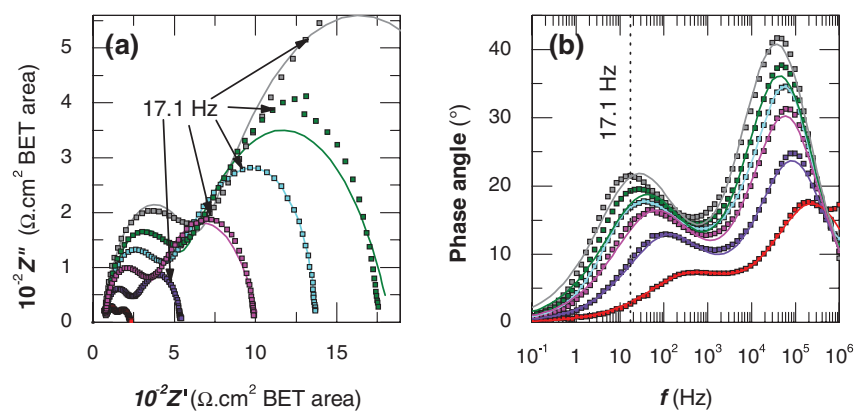

Figure 15. Cathodic impedance spectra of $\mathrm{WS}_{2}$ milled for 24 hours in $1.8 \mathrm{M} \mathrm{Na}_{2} \mathrm{~S}_{2.47}$ and $1 \mathrm{M} \mathrm{NaOH}$, at $35^{\circ} \mathrm{C}$. Measured at overpotentials of $-0.256 \mathrm{~V}(-\square) ;-0.179 \mathrm{~V}(-\square) ;-0.104 \mathrm{~V}(-\square) ;-0.076 \mathrm{~V}(-\square)$ $-0.047 \mathrm{~V}(-\square) ; 0 \mathrm{~V}\left(\square-\square^{-}\right.$. Squares correspond to experimental data, lines correspond to simulation. Represented as (a) Nyquist plot and (b) Bode phase angle plot. $Z^{\prime \prime}$ represents the imaginary component of the impedance, and $Z^{\prime}$ represents the real component.
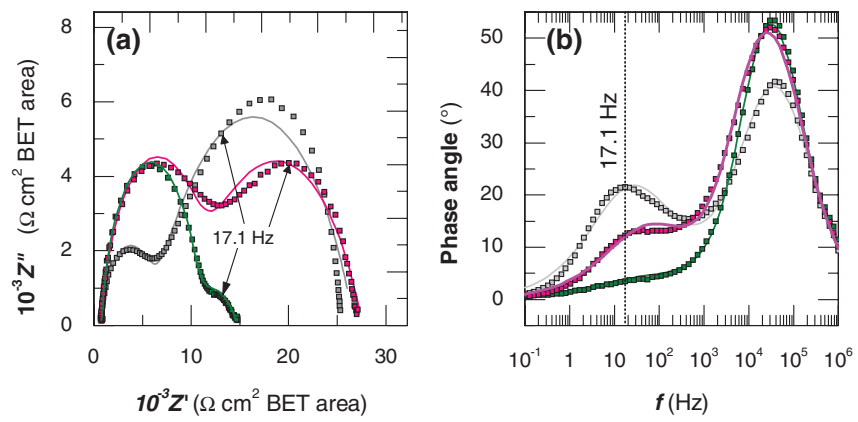

Figure 16. Anodic impedance spectra of $\mathrm{WS}_{2}$ milled for 24 hours in $1.8 \mathrm{M}$ $\mathrm{Na}_{2} \mathrm{~S}_{2.47}$ and $1 \mathrm{M} \mathrm{NaOH}$, at $35^{\circ} \mathrm{C}$. Measured at overpotentials of $0 \mathrm{~V}\left(\square^{-}\right)$, $+0.108 \mathrm{~V}(--)$ and $+0.216 \mathrm{~V}(-\square)$; Squares correspond to experimental data, lines correspond to simulation. Represented as (a) Nyquist plot and (b) Bode phase angle plot. origin of this feature is a solid-state contact resistance. Evidence for this is provided by the capacitances, $C_{2}$, for this feature in Table IV, estimated using the relation: ${ }^{81,82}$

$$
C=Q^{1 / n} R^{((1 / n)-1)}
$$

Where $Q$ and $n$ are the fitting parameters of the CPE. The values are roughly the same for all samples, at $\sim 20$ to $30 \mathrm{nF} \mathrm{cm}^{-2}$; these values are far too low for an electrochemical double layer capacitance, but more likely to be related to a solid state contact. ${ }^{79,83}$ The notion that a solid state contact resistance could play such a significant role is unsurprising; the difficulties of making "Ohmic contacts" to layered semiconductor electrodes are well documented. ${ }^{83,84}$ A very similar feature was also observed by Conway and Liu upon their $\mathrm{Co}_{3} \mathrm{O}_{4}$ electrocatalysts, due to the interface with a $\mathrm{Ti}$ substrate. ${ }^{85}$ the low frequency capacitance, $C_{1}$, of the milled $\mathrm{WS}_{2}$ is around an order of magnitude higher than the equivalent values for the unmilled $\mathrm{WS}_{2}$. (not shown) This could suggest that the milled $\mathrm{WS}_{2}$ has an intrinsically higher electrochemically active surface area or a larger concentration of active sites.

Figure 18 compares the resistances $R_{1}$ and $R_{2}$ for the different $\mathrm{WS}_{2}$ catalysts. Clearly, the difference between $R_{2}$ and $R_{1}$ is much smaller for IF-WS ${ }_{2}$ and the milled $\mathrm{WS}_{2}$ than for the unmilled $2 \mathrm{H}$ $\mathrm{WS}_{2}$. Indeed, in the case of the milled $\mathrm{WS}_{2}$, at $\eta>+150 \mathrm{mV}$, the contact resistance, $R_{2}$ is greater than the charge transfer resistance $R_{1}$. This suggests that at these high anodic potentials, an increase in overpotential, $\Delta \eta$, is applied to a greater extent over the solid-solid interface than the electrochemical interface.

Using $R_{1}$ and $R_{2}$, we may estimate the relative contribution of the contact resistance, and the kinetic resistance, $R_{1}$ to the overpotential. Since:

$$
\frac{\mathrm{d} E}{\mathrm{~d} i_{\mathrm{SS}}}=Z_{\mathrm{F}}(f \rightarrow 0)=R_{1}+R_{2}
$$




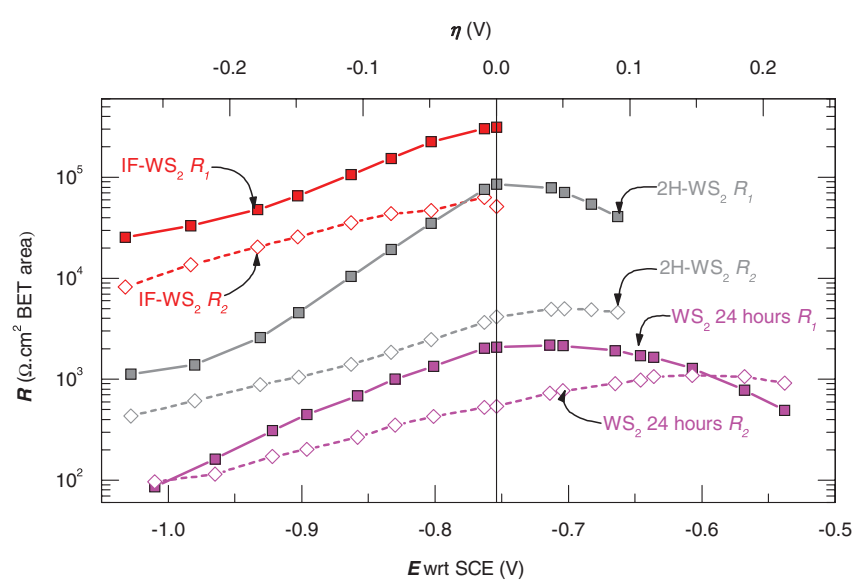

Figure 18. Comparison of resistances $R_{1}$ and $R_{2}$ for different $\mathrm{WS}_{2}$ samples, determined from fits of impedance data. Taken at $35^{\circ} \mathrm{C}$ in $1.8 \mathrm{M} \mathrm{Na}_{2} \mathrm{~S}_{2.47}$ and $1 \mathrm{M} \mathrm{NaOH}$. Filled squares represent the charge transfer resistance $R_{1}$ :

$(--)$, hollow diamonds represent the contact resistance, $R_{2}(\diamond)$ with lines connecting data points to aid visualization.

assuming linear behavior, for a small change in steady state current density, $\Delta i_{S S}$, there is a corresponding change in potential across the interface:

$$
\Delta \eta=\Delta i_{\mathrm{SS}}\left(R_{1}+R_{2}\right)=\Delta \eta_{1}+\Delta \eta_{2}
$$

where $\Delta \eta_{1}$ and $\Delta \eta_{2}$ are the contributions to the change in potential from $R_{1}$ and $R_{2}$, respectively, when the current is increased by an amount $\Delta i_{\text {SSs. }}$. At each point where an impedance spectrum is taken, there will be a steady state DC current density, $i_{\text {SS }}$. By summing up the $\Delta \eta$ for each incremental increase in $i_{\mathrm{SS}}$, it is then possible to estimate $\eta_{1}$ and $\eta_{2}$, the contributions to the overpotential from the $R_{1}$ and $R_{2}$, as a function of $i_{\text {SS }}$. A similar approach was taken by Wagner to estimate the individual contributions to the total overpotential of a polymer electrolyte membrane fuel cell. ${ }^{86}$

The results of this analysis are shown on Figure 19a, 19b and 19c for the unmilled $\mathrm{WS}_{2}$, the milled $\mathrm{WS}_{2}$ and the IF-WS 2 , respectively. For the unmilled sample only a small part of the overpotential seems to arise from the contact resistance. However, for the IF-WS $\mathrm{W}_{2}$ and the milled $\mathrm{WS}_{2}$ it is much more significant, especially at high overpotentials: up to $\sim 30 \%$ of the overpotential is due to the contact resistance on the milled $\mathrm{WS}_{2}$, and $\sim 25 \%$ for the IF-WS

The insets on Figure 19a, 19b and 19c compare the polarization curves simulated from the impedance data, and the actual polarization curves from the potentiostatic data shown in Figure 14. In general, the simulated curves correspond closely to the actual polarization curves, validating this approach whereby impedance spectroscopy is used to describe the polarization of the $\mathrm{WS}_{2}$ catalysts.

Using the data shown from Figure 19, it is now possible to estimate the hypothetical activity of the different catalysts in the absence of the contact resistance, in which case the current should be controlled by kinetics. The simulated kinetic polarization plots of the catalysts are shown on Figure 20. In the case of the milled $\mathrm{WS}_{2}$, the plots are linear in both the anodic and cathodic regions, and show no inflection, similar to those of the $2 \mathrm{H}-\mathrm{WS}_{2}$. The simulated curve of the IF-WS is not as linear, but nevertheless a single Tafel slope can be fitted over the entire cathodic range more satisfactorily than in the polarization plots shown in Figure 17.

The Tafel parameters from these plots are summarized in Table V. The simulated exchange current densities, and some of the Tafel slopes are very similar in magnitude to the low overpotential values from Table III. The simulated Tafel slopes all range between 100 and $135 \mathrm{mV}$ decade $^{-1}$. These values are within the typical range for a kinetically controlled current, ${ }^{80}$ and much lower than the apparent Tafel slopes for these materials at high overpotentials on Table III. (a) Unmilled $\mathrm{WS}_{2}$

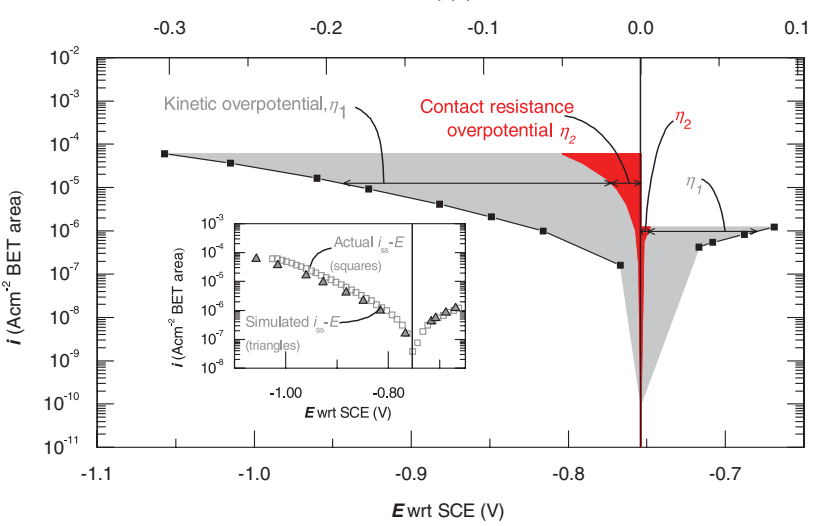

(b) IF-WS

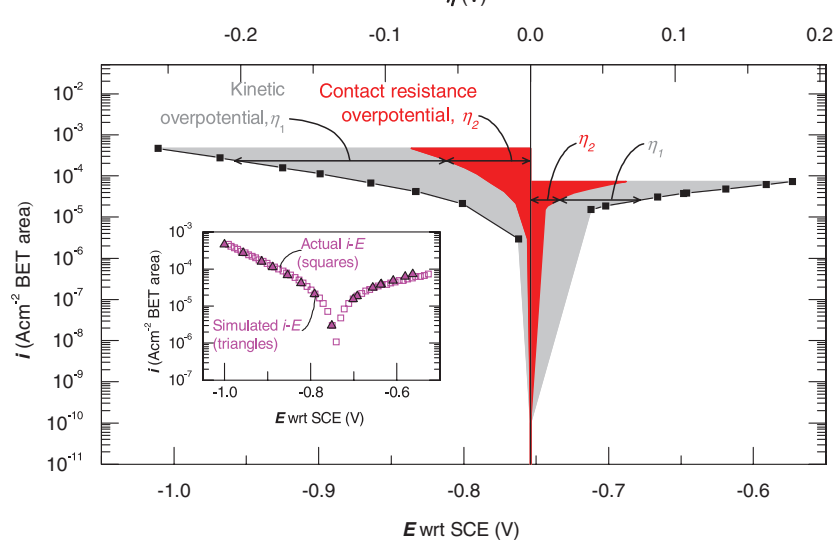

(c) IF-WS

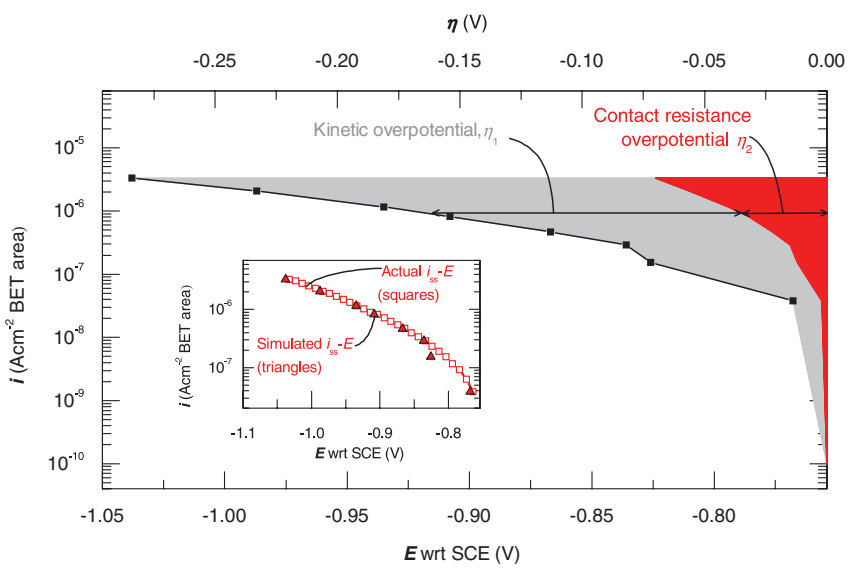

Figure 19. Comparison of $\eta_{1}$ and $\eta_{2}$, for (a) unmilled $\mathrm{WS}_{2}$, (b) the $\mathrm{WS}_{2}$ milled for 24 hours, and (b) IF-WS 2 , determined from impedance data. Taken at $35^{\circ} \mathrm{C}$ in $1.8 \mathrm{M} \mathrm{Na}_{2} \mathrm{~S}_{2.47}$ and $1 \mathrm{M} \mathrm{NaOH}$. Shaded gray area represents kinetic contribution to overpotential, $\eta_{1}(\square)$; shaded red area represents contribution from contact resistance, $\eta_{2}(\square)$; black squares show simulated total overpotential, $\eta,(-\boldsymbol{C})$, with lines connecting data points to ease visualization. The inset compares the polarization curve simulated from the impedance data $(\boldsymbol{\Delta})$, to the actual polarization curve measured from the potentiostatic data $(\square)$.

Finally, it is also of interest to compare the kinetic activity of the different catalysts, using the data presented in Figure 20. The milled $\mathrm{WS}_{2}$ is 30 to 40 times more active than the unmilled $2 \mathrm{H}-\mathrm{WS}_{2}$. Conversely, the $2 \mathrm{H}-\mathrm{WS}_{2}$ shows a 4 to 10 fold increase in activity over the IF-WS . $_{2}$ 


\section{Table V. Tafel parameters for different $\mathrm{WS}_{2}$ samples, using simulated kinetic polarization plots from data presented in Figure 20. The errors} shown are the standard deviation in each fit.

\begin{tabular}{|c|c|c|c|c|}
\hline Catalyst & $\eta(\mathrm{V})$ & $10^{3} b\left(\mathrm{~V} \mathrm{decade}^{-1}\right)$ & $10^{6} i_{0}\left(\mathrm{~A} \mathrm{mg}^{-1}\right)$ & $10^{8} i_{0}\left(\mathrm{~A} \mathrm{~cm}{ }^{-2} \mathrm{BET}\right.$ area $)$ \\
\hline \multicolumn{5}{|l|}{ Cathodic region } \\
\hline Unmilled $2 \mathrm{H}-\mathrm{WS}_{2}$ & -0.253 to -0.059 & $103 \pm 2$ & $7.7 \pm 0.4$ & $28 \pm 2$ \\
\hline $\mathrm{WS}_{2}$ milled for 24 hours & -0.176 to -0.061 & $112 \pm 1$ & $283 \pm 8$ & $1200 \pm 30$ \\
\hline $\mathrm{IF}-\mathrm{WS}_{2}$ & -0.214 to -0.060 & $125 \pm 10$ & $5 \pm 1$ & $7 \pm 2$ \\
\hline \multicolumn{5}{|l|}{ Anodic region } \\
\hline $2 \mathrm{H}-\mathrm{WS}_{2}$ & +0.044 to +0.080 & $104 \pm 4$ & $5.8 \pm 0.3$ & $21 \pm 1$ \\
\hline $\mathrm{WS}_{2}$ milled for 24 hours & +0.052 to +0.181 & $135 \pm 4$ & $240 \pm 10$ & $1020 \pm 50$ \\
\hline
\end{tabular}

\section{Discussion}

Structure dependence of electrocatalytic activity. - Evidently, the materials under study exhibit a wide range of electrocatalytic activity for polysulfide reduction and oxidation, spanning over two orders of magnitude. These can be explained by considering the differences in structure between each material.

The microstructural characterization showed that each catalyst has roughly the same bulk composition and crystal structure. However, distinct morphological differences were observed between each catalyst, especially with respect to the predominance of edge planes on their surfaces. The proportion of edge planes increases in the same order as the catalyst activity: IF-WS $2<$ unmilled $2 \mathrm{H}-\mathrm{WS}_{2}<$ milled $\mathrm{WS}_{2}$. Thus the most simple and unambiguous explanation for the trends observed is that the edge planes are the active sites for polysulfide reduction and oxidation. On this basis, the differences in activity observed are primarily due to the number of edge planes present on each catalyst. This is completely consistent with previous theoretical and experimental investigations of similar materials for other catalytic reactions. ${ }^{34,35,46,50,51}$

Nonetheless, more complicated explanations could also account for the trends we observed. We acknowledge that the sites that dominate the catalytic activity may not be equivalent on each material. This is especially true for the milled $\mathrm{WS}_{2}$, since it was prepared at room temperature under conditions that were far from equilibrium. Therefore, a large number of metastable defects could have formed. Such defects would not be present on the unmilled $2 \mathrm{H}-\mathrm{WS}_{2}$ and the $\mathrm{IF}_{-\mathrm{WS}_{2}}$, as these catalysts would have been synthesized at higher temperatures under more equilibrium conditions.

Moreover, each catalyst could contain different impurities that would strongly influence their activity. However, the EDX analyzes performed on all the catalysts under study were unable to detect any metallic impurities, within the detection limit of $\sim 0.1 \% .{ }^{75}$ Notably,

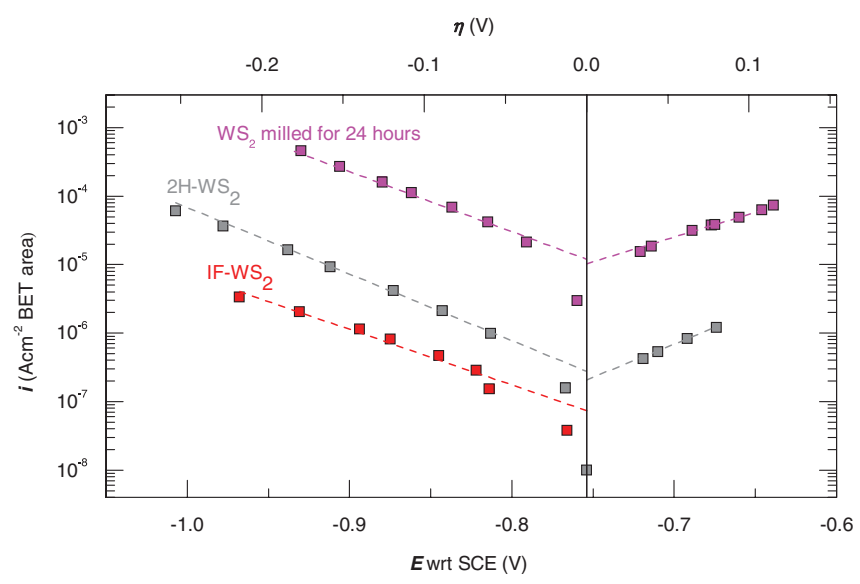

Figure 20. Simulated kinetic polarization response of different $\mathrm{WS}_{2}$, based on $i-\eta_{1}$ data, determined from impedance spectroscopy measurements. Taken at $35^{\circ} \mathrm{C}$ in $1.8 \mathrm{M} \mathrm{Na}_{2} \mathrm{~S}_{2.47}$ and $1 \mathrm{M} \mathrm{NaOH}$. The straight lines show the fitted Tafel slopes. there is a small additional peak in the XRD trace for the milled $\mathrm{WS}_{2}$. Taking into account the EDX analysis, this feature can probably be attributed to the formation of an additional phase containing a combination of $\mathrm{W}, \mathrm{S}$ and possibly $\mathrm{O}$. In any case, the diminutive size of this XRD peak suggests that the phase it represents would only constitute a very small proportion of the total bulk composition. We cannot completely neglect the possibility that the small amount of $\mathrm{O}$ detected in our EDX analysis could play some role in the catalysis. However, it is worth noting that solution phase sulfide species will adsorb spontaneously onto most surfaces to form surface sulfides, ${ }^{27,87-96}$ Consequently, even though oxygen is detected on the catalyst, ex-situ, prior to exposure to the polysulfide electrolyte, we anticipate that the surface is more likely comprised of a sulfide, as opposed to oxide phase, as suggested by Licht ${ }^{30}$ and Hodes. ${ }^{21}$

Solid state contact resistance.- Impedance spectroscopy elucidated the influence of the contact resistance on the polarization response of the catalysts tested. Non-metallic, poorly conducting electrocatalysts have received increasing attention in recent years for energy conversion processes, in particular those based on sulfides ${ }^{34-36,97}$ and oxides. ${ }^{98-103}$ However, in many cases, it seems possible that the role of the contact resistance on the performance of the catalyst could be overlooked. Without accounting for such solid state effects, it is difficult to assess the true electrocatalytic activity of a non-metallic surface.

Reaction kinetics. - It is interesting to note the similarities between the electrochemical response of all the different samples. The same equivalent circuit could be used to model each material's impedance spectra. In particular, there only seems to be one relaxation attributable to electrochemical kinetics, due to the parallel combination of $R_{1}$ and $\mathrm{CPE}_{1}$. The absence of an additional relaxation at low frequencies suggests that $R_{1}$ corresponds to a coverage independent charge transfer resistance, $R_{\mathrm{CT}}{ }^{104-106}$ This would mean that the coverage term, $\theta$, or $(1-\theta)$ in the rate equation of the rate determining step should have reached its potential independent value. The linearity of the simulated kinetic polarization plots of Figure 20 indicate that a single kinetic regime prevails for polysulfide reduction and a single kinetic regime prevails for polysulfide oxidation

Mass transport and anodic passivation.- Several authors have observed the 'passivation' of their electrodes during polysulfide oxidation due to the formation of a S film. ${ }^{7-9,29,107-109}$ Zhou et al. propose that efficient mass transport can prevent this anodic passivation. ${ }^{9}$ Presumably, mass transport alleviates the passivation as a result of the autocatalytic effect that polysulfides seem to exhibit upon the dissolution of the S layer. ${ }^{29,107-109}$

On the catalysts tested here, there were no obvious signs that the current was controlled by mass transport, as the electrochemical response was unaffected by the absence of a stirrer. Indeed, a conventional mass transport limitation should manifest itself as a Warburg feature in the impedance spectra. ${ }^{110}$ It is possible that mass transport effects could be observable in more dilute solutions, or at higher current densities or potentials. 
Although we find no evidence to suggest that there are mass transport restrictions under our experimental conditions, we speculate that some other kind of passivation, unrelated to mass transport, could be the cause of the steady decrease in anodic activity of the milled $\mathrm{WS}_{2}$, with cycling. This effect can be observed by comparing Figure 12 and Figure 13. The lower anodic activity of the potentiostatic measurement, relative to the potentiodynamic measurement, on Figure 13 and Figure 14, respectively, could also be symptomatic of this phenomenon.

Since anodic passivation is a cause of inefficiency in $\mathrm{S}_{x}^{2-}-\mathrm{Br}$ redox flow batteries, ${ }^{7,8}$ it is worth contemplating upon its origin. The nucleation of the $S$ phase most probably occurs at specific sites or ensembles. Moreover, its formation may not necessarily be directly associated with the main reaction pathway for polysulfide oxidation. In that respect, we speculate that the $S$ poisoning described here could be similar to the graphite poisoning on $\mathrm{Ni}$ catalysts during the water gas shift reaction. ${ }^{111}$ It appears that the $\mathrm{WS}_{2}$ is only slightly susceptible to anodic passivation (if it all), and this may be because it lacks the sites or ensembles which favor S nucleation.

Catalyst activity. - At the beginning of this article, we estimated that in order for a polysulfide bromine redox flow battery to be cost effective, an exchange current density of $\sim 0.7$ to $\sim 1 \mathrm{~mA} \mathrm{~cm}{ }^{-2}$ real surface area would be required. Although ball milling resulted in considerable improvements in the electrocatalytic performance of $\mathrm{WS}_{2}$, its exchange current density, at $\sim 0.012 \mathrm{mAcm}^{-2}$, is still a factor of 60-70 short of the required performance. Moreover, this figure does not even take into account other important factors such as catalyst dispersion, the effect of contact resistance and stability.

Nonetheless, the electrocatalysis of polysulfide reduction and oxidation is a poorly explored field and there should be ample opportunities for further improvements. Its optimisation should be possible by capitalizing upon the wealth of information already known about the catalytic properties of transition metal sulfides.

Further improvements to catalyst performance?.- In the present study, only a limited number of catalysts have been tested for polysulfide reduction and oxidation. Several of the catalysts already tested in the literature are likely to be more active than those tested here. However, previous studies did not attempt to determine the inherent activity of particulate electrocatalysts for polysulfide reduction and oxidation, normalized according to their 'true' surface area. This makes it difficult to make a fair comparison between different studies. However, a large number of nanostructured sulfide catalysts have been tested for use in the petrochemical industry, ${ }^{32,33,37}$ whereas very few of these have been tested for polysulfide reduction and oxidation. Fruitful strategies could be to 'promote' the activity of $\mathrm{WS}_{2}$ and other metal sulfides by incorporating more than one metallic element into the catalysts. ${ }^{32,36,45,112,113}$

Each of the catalysts tested here had a uniformly low surface area, ranging from $\sim 2$ to $\sim 6 \mathrm{~m}^{2} \mathrm{~g}^{-1}$. For their experimental characterization, this was beneficial; it would be difficult to make a fair comparison of catalyst activity if they exhibited widely different surface areas. Conversely, for their industrial application, a much higher surface area would be necessary in order to maximize the catalyst utilization. For instance, C-supported Pt electrocatalysts in a polymer electrolyte membrane (PEM) fuel cell have typical surface areas of $\sim 70$ to $\sim 80 \mathrm{~m}^{2} \mathrm{~g}^{-1} .{ }^{20}$ Notably, the investigations of Kouzu et al. ${ }^{55}$ suggest that such high surface areas are also obtainable using the type of sulfide catalysts investigated here. Their ball milled $\mathrm{MoS}_{2}$ had a surface area of $\sim 80 \mathrm{~m}^{2} \mathrm{~g}^{-1}$. The primary difference between their synthesis method and that which was used here is their addition of butanol to the mill, which presumably acted as a stabilizing agent. Improved dispersion should also be achievable using a high surface area $\mathrm{C}$ support such as those used in PEM fuel cells. A viable one-step process to produce a supported catalyst could be to co-grind the $\mathrm{WS}_{2}$ with a high surface area $\mathrm{C}$ support (possibly with a stabilizing agent such as butanol).
The solid state contact resistance observed here would result in significant efficiency losses in a $\mathrm{S}_{\mathrm{x}}^{2-}$ - $\mathrm{Br}$ redox flow battery, especially at high current densities. Methods of avoiding such poor contacts are usually found empirically, either by doping the semiconducting electrode or changing the support. ${ }^{83}$ Indeed, it is conceivable that this problem is a characteristic of the sticky carbon composite, and would not manifest itself on a support with a different composition.

\section{Conclusions}

In this study, a combination of ex-situ characterization methods and electrochemical experiments were used to study the factors controlling the activity of particulate $\mathrm{WS}_{2}$ electrocatalysts. We found that the catalyst activity increased in the following order: IF-WS $\mathrm{W}_{2}<$ unmilled $2 \mathrm{H}-\mathrm{WS}_{2}<$ milled $\mathrm{WS}_{2}$, in correlation with the number of edge planes at the catalyst surface. This trend is consistent with other investigations of similar metal sulfides but for different reactions. ${ }^{34,49-51,55}$ This suggests that the factors governing their activity toward polysulfide reduction and oxidation are similar to those for other catalytic systems. We conclude our work by proposing several promising avenues toward the optimal electrocatalysis of polysulfide reduction and oxidation

\section{Acknowledgments}

We are most grateful to Reshef Tenne and Nanomaterials Ltd for providing the catalyst material. The authors are grateful for the technical support from David Vowles, Mary Vickers, Zlatko Saracevic and Andrew Moss. IELS acknowledges funding from the Engineering and Physical Sciences Research Council, Regenesys Technologies Ltd and The Worshipful Company of Armorers and Brasiers.

\section{References}

1. P. J. Hall, Energy Policy, 36, 4363 (2008).

2. P. J. Hall and E. J. Bain, Energy Policy, 36, 4352 (2008)

3. D. U. Sauer, The demand for energy storage in regenerative energy systems, in First International Renewable Energy Storage Conference, Gelsenkirchen (2006).

4. D. U. Sauer, Energy storage in grid with high penetration of renewable energies, in DAAD Seminar for young Russian engineers in Electrical Engineering, Aachen (2007)

5. A. C. R. Price, in Renewable Energy Sources - its role in Renewables and Future Electricity Markets, p. 11, Institute of Mechanical Engineers, London (2000).

6. A. C. R. Price, S. Bartley, S. Male, and G. Cooley, Power Engineering Journal, 13, 122 (1999)

7. S. H. Ge, B. L. Yi, and H. M. Zhang, J. Appl. Electrochem., 34, 181 (2004).

8. P. Zhao, H. M. Zhang, H. T. Zhou, and B. L. Yi, Electrochimica Acta, 51, 1091 (2005)

9. H. T. Zhou, H. M. Zhang, P. Zhao, and B. L. Yi, Electrochimica Acta, 51, 6304 (2006).

10. P. M. Lessner, F. R. McLarnon, J. Winnick, and E. J. Cairns, J. Electrochem. Soc., 140, 1847 (1993)

11. C. Ponce de León, A. Frias-Ferrer, J. Gonzalez-Garcia, D. A. Szanto, and F. C. Walsh, Journal of Power Sources, 160, 716 (2006).

12. A. Z. Weber, M. M. Mench, J. P. Meyers, P. N. Ross, J. T. Gostick, and Q. H. Liu, J. Appl. Electrochem., 41, 1137 (2011).

13. S. Licht, J. Electrochem. Soc., 134, 2137 (1987).

14. G. Chiu and R. D. Eubanks, Mikrochimica Acta, 2, 145 (1989).

15. P. Scheffler, Environmental Assessment $20 \mathrm{MW}$ Windfarm and Associated Energy Storage Facility, in, T. V. Authority Editor (2002).

16. P. Denholm and G. L. Kulcinski, Energy Conversion and Management, 45, 2153 (2004)

17. D. P. Scamman, G. W. Reade, and E. P. L. Roberts, Journal of Power Sources, 189 , 1220 (2009).

18. D. P. Scamman, G. W. Reade, and E. P. L. Roberts, Journal of Power Sources, 189 , 1231 (2009)

19. I. E. L. Stephens, Polysulfide electrocatalysis at transition metal sulfides, in Department of Materials Science and Metallurgy, University of Cambridge (2010).

20. H. A. Gasteiger, S. S. Kocha, B. Sompalli, and F. T. Wagner, Appl. Catal. B-Envi ron., 56, 9 (2005).

21. G. Hodes, J. Manassen, and D. Cahen, J. Appl. Electrochem., 7, 181 (1977).

22. G. Hodes, J. Manassen, and D. Cahen, J. Electrochem. Soc., 127, 544 (1980)

23. R. J. Remick and E. H. Camara, Electrochemistry of the Sulfide/Polysulfide Couple, in Lawrence Berkeley Laboratory Report, Lawrence Berkeley Laboratory Report (1983)

24. P. Lessner, F. R. McLarnon, J. Winnick, and E. J. Cairns, J. Electrochem. Soc., 134, 2669 (1987). 
25. P. Lessner, Kinetics and Transport Processes in Aqueous Polysulfide Electrode Reactions, in Chemical Engineering, University of California, Berkeley (1986).

26. A. J. Ahern, Oxide and Sulphide Electrochemistry at Solid Electrodes, in Department of Chemistry, National University of Ireland, Cork (2002).

27. D. V. Esposito, K. D. Dobson, B. E. McCandless, R. W. Birkmire, and J. G. Chen, J. Electrochem. Soc., 156, B962 (2009).

28. P. M. Lessner, F. R. McLarnon, J. Winnick, and E. J. Cairns, J. Appl. Electrochem., 22, 927 (1992)

29. P. L. Allen and A. Hickling, Transactions of the Faraday Society, 53, 1626 (1957).

30. S. Licht, J. Electrochem. Soc., 135, 258 (1988).

31. M. Jormakka, K. Yokoyama, T. Yano, M. Tamakoshi, S. Akimoto, T. Shimamura, P. Curmi, and S. Iwata, Nature Structural \& Molecular Biology, 15, 730 (2008).

32. F. Besenbacher, M. Brorson, B. S. Clausen, S. Helveg, B. Hinnemann, J. Kibsgaard, J. Lauritsen, P. G. Moses, J. K. Nørskov, and H. Topsoe, Catal. Today, 130, 86 (2008).

33. R. R. Chianelli, M. H. Siadati, M. P. De la Rosa, G. Berhault, J. P. Wilcoxon, R. Bearden, and B. L. Abrams, Catalysis Reviews-Science and Engineering, 48, 1 (2006).

34. T. F. Jaramillo, K. P. Jorgensen, J. Bonde, J. H. Nielsen, S. Horch, and I. Chorkendorff, Science, 317, 100 (2007).

35. B. Hinnemann, P. G. Moses, J. Bonde, K. P. Jorgensen, J. H. Nielsen, S. Horch, I. Chorkendorff, and J. K. Nørskov, J. Am. Chem. Soc., 127, 5308 (2005).

36. J. Bonde, P. G. Moses, T. F. Jaramillo, J. K. Nørskov, and I. Chorkendorff, Faraday Discussions, 140, 219 (2008).

37. R. R. Chianelli, G. Berhault, and B. Torres, Catal. Today, 147, 275 (2009)

38. D. Merki, S. Fierro, H. Vrubel, and X. Hu, Chemical Science, (2011).

39. Y. Li, H. Wang, L. Xie, Y. Liang, G. Hong, and H. Dai, J. Am. Chem. Soc., 133, 7296 (2011)

40. D. Merki and X. Hu, Energy Environ. Sci., 4, (2011).

41. H. Vrubel, D. Merki, and X. Hu, Energy Environ. Sci., (2012).

42. B. Seger, A. B. Laursen, P. C. K. Vesborg, T. Pedersen, O. Hansen, S. Dahl, and I. Chorkendorff, Angewandte Chemie (International ed. in English), 51, 9128 (2012).

43. C. N. R. Rao and K. P. R. Pisharody, Progress in Solid State Chemistry, 10, 207 (1976).

44. F. Kopnov, R. Tenne, B. Späth, W. Jägermann, H. Cohen, Y. Feldman, A. Zak, A. Moshkovich, and L. Rapoport, in Functionalized Nanoscale Materials, Devices and Systems, p. 51 (2008).

45. P. G. Moses, B. Hinnemann, H. Topsoe, and J. K. Nørskov, J. Catal., 268, 201 (2009).

46. J. V. Lauritsen, M. Nyberg, R. T. Vang, M. V. Bollinger, B. S. Clausen, H. Topsoe, K. W. Jacobsen, E. Laegsgaard, J. K. Nørskov, and F. Besenbacher, Nanotechnology, 14, 385 (2003).

47. P. G. Moses, Transition metal sulfide catalysts - a DFT study of structure and reactivity, in Department of Physics, Technical University of Denmark, Kgs. Lyngby (2008).

48. E. M. Fernandez, P. G. Moses, A. Toftelund, H. A. Hansen, J. I. Martinez, F. Abild-Pedersen, J. Kleis, B. Hinnemann, J. Rossmeisl, T. Bligaard, and J. K. Nørskov, Angew. Chem.-Int. Edit., 47, 4683 (2008).

49. S. M. Ahmed and H. Gerischer, Electrochimica Acta, 24, 705 (1979).

50. M. Salmeron, G. A. Somorjai, A. Wold, R. Chianelli, and K. S. Liang, Chem. Phys. Lett., 90, 105 (1982).

51. A. B. Laursen, S. Kegnaes, S. Dahl, and I. Chorkendorff, Energy Environ. Sci., 5, (2012).

52. R. Tenne and G. Seifert, Annual Review of Materials Research, 39, 387 (2009).

53. F. Y. Cheng, J. Chen, and X. L. Gou, Advanced Materials, 18, 2561 (2006).

54. J. Chen, S. L. Li, Q. Xu, and K. Tanaka, Chemical Communications, 1722 (2002).

55. M. Kouzu, K. Uchida, Y. Kuriki, and F. Ikazaki, Appl. Catal. A-Gen., 276, 241 (2004).

56. M. Polyakov, S. Indris, S. Schwamborn, A. Mazheika, M. Poisot, L. Kienle W. Bensch, M. Muhler, and W. Grunert, J. Catal., 260, 236 (2008).

57. Y. Tsverin, R. Popovitz-Biro, Y. Feldman, R. Tenne, M. R. Komarneni, Z. Q. Yu, A. Chakradhar, A. Sand, and U. Burghaus, Mater. Res. Bull., 47, 1653 (2012).

58. Y. Tsverin, T. Livneh, R. Rosentsveig, A. Zak, I. Pinkas, and R. Tenne, Nanomaterials and Energy, 2, 25 (2012).

59. R. Jenkins and R. Snyder, Introduction to Powder Diffractometry, WileyInterscience (1996).

60. J. I. Langford, A. Boultif, J. P. Auffredic, and D. Louer, Journal of Applied Crystallography, 26, 22 (1993).

61. P. A. Webb and C. Orr, Analytical Methods in Fine Particle Technology, Micromeritics Instrument Company, Norgross, Georgia (1997).

62. Y. Feldman, A. Zak, R. Popovitz-Biro, and R. Tenne, Solid State Sciences, 2, 663 (2000).

63. S. Trasatti, Electrochimica Acta, 29, 1503 (1984).

64. J. W. Long, K. E. Ayers, and D. R. Rolison, J. Electroanal. Chem., 522, 58 (2002).

65. J. W. Long and D. R. Rolison, in New Directions in Electroanalytical Chemistry II, J. Leddy, P. Vanysek, and M. D. Porter Editors, Pennington, New Jersey (1999).

66. D. J. G. Ives and G. Janz, Reference electrodes, theory and practice, Academic Press, New York (1961).

67. F. Mansfeld, S. Lin, Y. C. Chen, and H. Shih, J. Electrochem. Soc., 135, 906 (1988)

68. G. Kimmel and D. Dayan, in Defect and Microstructure Analysis by Diffraction, p. 698, Oxford University Press, Oxford (1999).
69. S. K. Chen, B. A. Glowacki, J. L. MacManus-Driscoll, M. E. Vickers, and M. Majoros, Superconductor Science \& Technology, 17, 243 (2004).

70. L. Margulis, G. Salitra, R. Tenne, and M. Talianker, Nature, 365, 113 (1993).

71. M. Behrens, F. Studt, I. Kasatkin, S. Kuhl, M. Havecker, F. Abild-Pedersen, S. Zander, F. Girgsdies, P. Kurr, B. L. Kniep, M. Tovar, R. W. Fischer, J. K. Norskov, and R. Schlogl, Science, 336, 893 (2012).

72. S. Helveg, J. V. Lauritsen, E. Laegsgaard, I. Stensgaard, J. K. Norskov, B. S. Clausen, H. Topsoe, and F. Besenbacher, Physical Review Letters, 84, 951 (2000).

73. M. Bar-Sadan, A. N. Enyashin, S. Gemming, R. Popovitz-Biro, S. Y. Hong, Y. Prior, R. Tenne, and G. Seifert, Journal of Physical Chemistry B, 110, 25399 (2006).

74. J. Kibsgaard, Z. B. Chen, B. N. Reinecke, and T. F. Jaramillo, Nature Materials, 11, 963 (2012).

75. J. I. Goldstein, D. E. Newbury, P. Echlin, D. C. Joy, C. Fiori, and E. Lifshin, in Scanning Electron Microscopy and X-Ray Microanalysis, Third ed., p. 355, Plenum Press, London (2003).

76. F. Kopnov, A. Yoffe, G. Leitus, and R. Tenne, Physica Status Solidi B-Basic Solid State Physics, 243, 1229 (2006).

77. A. Teder, Sv. Papperstidn., 71, 149 (1968)

78. P. Lessner, J. Winnick, F. R. McLarnon, and E. J. Cairns, J. Electrochem. Soc., 133, 2517 (1986)

79. E. Gileadi, E. Kirowa-Eisner, and J. Penciner, Interfacial Electrochemistry: An Experimental Approach, Addison-Wesley Publishing Company, Inc., Reading, Massacusetts (1975).

80. J. O. Bockris and S. U. M. Khan, in Surface Electrochemistry: A Molecular Level Approach, p. 211, Springer Chichester (1993).

81. D. Chakraborty, I. Chorkendoff, and T. Johannessen, Journal of Power Sources, 162, 1010 (2006)

82. ZSimpWin Technical Notes, http://www.echemsw.com/note24.htm.

83. R. Memming, Semiconductor Electrochemistry, Wiley-VCH, Weinheim (2000).

84. M. Etman and M. Neumannspallart, J. Electroanal. Chem., 269, 411 (1989).

85. B. E. Conway and T. C. Liu, Berichte Der Bunsen-Gesellschaft-Physical Chemistry Chemical Physics, 91, 461 (1987).

86. N. Wagner, J. Appl. Electrochem., 32, 859 (2002).

87. P. G. Lustemberg, C. Vericat, G. A. Benitez, M. E. Vela, N. Tognalli, A. Fainstein, M. L. Martiarena, and R. C. Salvarezza, J. Phys. Chem. C, 112, 11394 (2008).

88. R. O. Lezna, N. R. Detacconi, and A. J. Arvia, J. Electroanal. Chem., 283, 319 (1990).

89. G. H. Kelsall and I. Thompson, J. Appl. Electrochem., 23, 287 (1993)

90. A. Briceno and S. Chander, J. Appl. Electrochem., 20, 512 (1990).

91. A. Briceno and S. Chander, J. Appl. Electrochem., 20, 506 (1990).

92. D. W. Hatchett, X. P. Gao, S. W. Catron, and H. S. White, J. Phys. Chem., 100, 331 (1996)

93. Y. E. Sung, W. Chrzanowski, A. Zolfaghari, G. Jerkiewicz, and A. Wieckowski, $J$ Am. Chem. Soc., 119, 194 (1997).

94. J. L. Zubimendi, R. C. Salvarezza, L. Vazquez, and A. J. Arvia, Langmuir, 12, 2 (1996).

95. F. H. Garzon and F. A. Uribe, in Handbook of Fuel Cells: : Advances in Electrocatalysis, Materials, Diagnostics and Durability, W. Vielstich, H. A. Gasteiger, and H. Yokakawa Editors, p. 265, John Wiley \& Sons, Chichester (2009).

96. C. Schlaup, D. Friebel, P. Broekmann, and K. Wandelt, Surf. Sci., 602, 864 (2008).

97. M. K. Wang, A. M. Anghel, B. Marsan, N. L. C. Ha, N. Pootrakulchote, S. M. Zakeeruddin, and M. Gratzel, J. Am. Chem. Soc., 131, 15976 (2009).

98. G. A. Somorjai, H. Frei, and J. Y. Park, J. Am. Chem. Soc., 131, 16589 (2009).

99. A. J. Esswein, M. J. McMurdo, P. N. Ross, A. T. Bell, and T. D. Tilley, J. Phys. Chem. C, 113, 15068 (2009).

100. F. Jiao and H. Frei, Angew. Chem.-Int. Edit., 48, 1841 (2009).

101. M. W. Kanan and D. G. Nocera, Science, 321, 1072 (2008).

102. J. Suntivich, H. A. Gasteiger, N. Yabuuchi, and Y. Shao-Horn, J. Electrochem. Soc., 157, B1263 (2010).

103. H.-Y. Su, Y. Gorlin, I. C. Man, F. Calle-Vallejo, J. K. Norskov, T. F. Jaramillo, and J. Rossmeisl, Physical Chemistry Chemical Physics, 14, 14010 (2012).

104. D. A. Harrington and B. E. Conway, Electrochimica Acta, 32, 1703 (1987).

105. R. D. Armstrong and M. Henderson, J. Electroanal. Chem., 39, 81 (1972).

106. L. Bai, D. A. Harrington, and B. E. Conway, Electrochimica Acta, 32, 1713 (1987).

107. J. Szynkarczuk, P. G. Komorowski, and J. C. Donini, Electrochimica Acta, 40, 487 (1995)

108. M. Behm and D. Simonsson, J. Appl. Electrochem., 27, 507 (1997).

109. S. Licht, Nature, 330, 148 (1987).

110. A. J. Bard and L. R. Faulkner, in Electrochemical Methods: Fundamentals and Applications, Second Edition ed., p. 368, John Wiley \& Sons, Inc., New York (2001).

111. F. Besenbacher, I. Chorkendorff, B. S. Clausen, B. Hammer, A. M. Molenbroek, J. K. Nørskov, and I. Stensgaard, Science, 279, 1913 (1998).

112. M. Brorson, A. Carlsson, and H. Topsoe, Catal. Today, 123, 31 (2007)

113. D. Merki, H. Vrubel, L. Rovelli, S. Fierro, and X. L. Hu, Chemical Science, 3, 2515 (2012).

114. Y. Q. Zhu, W. K. Hsu, H. Terrones, N. Grobert, B. H. Chang, M. Terrones, B. Q. Wei, H. W. Kroto, D. R. M. Walton, C. B. Boothroyd, I. Kinloch, G. Z. Chen, A. H. Windle, and D. J. Fray, Journal of Materials Chemistry, 10, 2570 (2000). 